UNIVERSIDADE DE SÃO PAULO

\title{
MONITORAMENTO E AVALIAÇÃO DAS PASSAGENS INFERIORES DE FAUNA PRESENTES NA RODOVIA SP- 225 NO MUNICÍPIO DE BROTAS, SÃO PAULO.
}

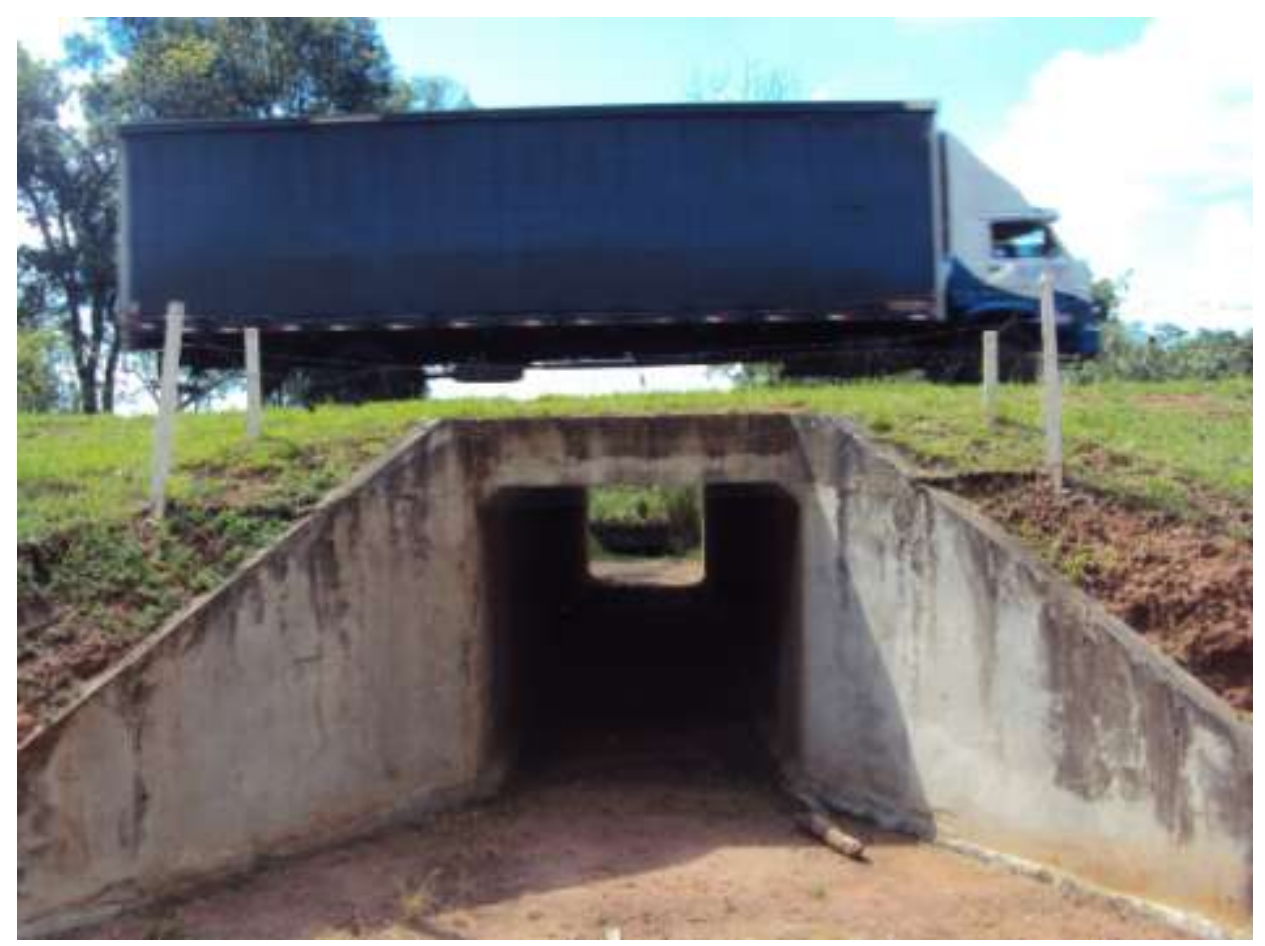

FERNANDA DELBORGO ABRA

SÃO PAULO 
FERNANDA DELBORGO ABRA

\title{
MONITORAMENTO E AVALIAÇÃO DAS PASSAGENS INFERIORES DE FAUNA PRESENTES NA RODOVIA SP- 225 NO MUNICÍPIO DE BROTAS, SÃO PAULO.
}

\author{
DISSERTAÇÃO APRESENTADA AO INSTITUTO \\ DE BIOCIÊNCIAS DA UNIVERSIDADE DE SÃO \\ PAULO PARA OBTENÇÃO DE TÍTULO DE \\ MESTRE EM ECOLOGIA DE AMBIENTES \\ AQUÁTICOS E TERRESTRES. \\ ORIENTADORA: PROFA. DRA. VÂNIA REGINA \\ PIVELLO
}

SÃO PAULO 


\section{Ficha Catalográfica}

Abra, Fernanda Delborgo

Monitoramento e avaliação das passagens inferiores de fauna presentes na rodovia SP-225 no município de Brotas, São Paulo.

\section{2 páginas}

Dissertação (Mestrado) - Departamento de Ecologia, Instituto de Biociências, Universidade de São Paulo.

1.Ecologia de Estradas 2. Passagem de fauna 3. Mamíferos de médio e grande porte. Departamento de Ecologia, Instituto de Biociências, Universidade de São Paulo.

Comissão julgadora

Prof. Dr. Prof. Dr.

Profa. Dra. Vânia Regina Pivello 
"Para tudo há um tempo, para cada coisa há um momento debaixo dos céus,

Tempo para nascer, e tempo para morrer; Tempo para plantar, e tempo para arrancar o que foi plantado; Tempo para matar, e tempo para sarar; Tempo para demolir, e tempo para construir; Tempo para chorar, e tempo para rir; Tempo para gemer, e tempo para dançar; Tempo para atirar pedras, e tempo para ajuntá-las; Tempo para dar abraços, e tempo para apartar-se; Tempo para procurar, e tempo para perder; Tempo para guardar, e tempo para jogar fora, Tempo para rasgar, e tempo para costurar; Tempo para calar, e tempo para falar; Tempo para amar, e tempo para odiar; Tempo para a guerra, e tempo para a paz." Eclesiastes 3: 1-8 
Eu agradeço...

Primeiramente à Deus pela excelência da criação, pelo amor incondicional, por todas as bênçãos que Ele sempre me dá, pela vida, pela saúde, pela família, pelas pessoas especiais com quem convivo e por tornar esse mestrado possível!

À minha querida mãe Sônia, minha melhor amiga, minha conselheira que sempre me deu e me dá o melhor, à quem eu recorro nos momentos de tristeza, dúvidas e aflição e encontro conforto, que me apóia em tudo que eu faço e é a minha melhor referência de como ser uma pessoa de bons valores. Eu amo muito, muito você mãe!

À minha querida irmã Juliana que me apóia, que sempre se esforçou em conviver da melhor maneira possível comigo, já que somos tão diferentes e por entender a importância desse mestrado pra mim;

À minha querida orientadora Vânia Pegina Pivello por ter aceitado me orientar, por toda paciência, carinho e o aprendizado que me proporcionou durante o mestrado;

Ao Doutorando Giordano Ciocheti pelas ajudas sempre bem vindas e por ser um parceiro para se trabalhar com Ecologia de Estradas!

Ao Dr. Milton Cezar Ribeiro, pela ajuda nas análises dos dados, obrigada pela atenção, e a simplicidade com que me recebeu!

Aos colegas do Lepac Alexandre Igari, Ana Luisa, Bete, Dani, Márcia, Thaís, Alessandra que sempre ajudaram;

Às queridas amigas Paula Prist e Mariane Biz com quem desabafei, pedi ajuda e pude desenvolver uma amizade maravilhosa durante o mestrado;

Às minhas amigas irmãs Ana Lívia e Juliana Hotta pelo laço maravilhoso de amizade e por elas tornarem tudo muito mais fácil e mais bonito!;

Às queridas "mães por adoção" Rita Cornélio, Ava Hotta, Marly Latorre e Nice Abra que são um exemplo pra mim de grandes mulheres!

Ao amigo irmão Raphael de Oliveira com quem eu posso contar em todos os momentos e que me ajudou muito durante toda a fase do mestrado, principalmente no dia de instalação das armadilhas de vídeo, carregando um gerador enorme nas costas, furando paredes e trabalhando muito como se o trabalho fosse dele! Muito, muito obrigada por tornar tudo mais agradável!

Aos queridos Marcel Huijser e Bethanie, amigos, parceiros em trabalho e ótimas companhias! Obrigada por me receberem tão bem na casa de vocês durante minha estadia em Montana! 
Aos queridos Judith e Shell que me acolheram em sua casa com muito carinho durante minha estadia em São Paulo. Vocês estarão para sempre no meu coração e eu espero retribuir tudo que vocês fizeram e fazem por mim.

À Centrovias que de pronto permitiu que eu realizasse o trabalho de campo nas passagens de fauna e que sempre foram tão acessíveis;

Ao Dr. Pedro Humberto Romanini da ARTESP pela ajuda e disponibilização de dados;

À Prefeitura Municipal de Brotas pelo apoio em logística e pelo apoio ao projeto;

Ao Janjão, Ana Lúcia e Alisângela da Secretaria de Meio Ambiente de Brotas e Luciana Pires de Jesus da Secretaria de Turismo de Brotas que me receberam tão bem e acreditaram desde o inicío no projeto, e pelas ótimas parcerias em diversos outros trabalhos;

À Abrotur que me cedeu hospedagem em diversas pousadas em Brotas durante meu trabalho de campo.

Ao Ecólogo Paulo Rufino, pesquisador científico da Fundação Florestal locado na Estação Ecológica de Itirapina pelas ótimas conversas sobre estradas e por todo o incentivo dado durante os trabalhos de campo;

Aos queridos assistentes de campo Cynthia Widmer, Paula Prist, Raphael de Oliveira, Josias Lopes, Leandra Morais, Leonardo Barszcz, Vinicius Dias, Sônia Delborgo e Paula Franco, pessoas com quem aprendi muito, troquei experiências, dei risadas e estarão pra sempre no meu coração.

À Eng. Agrônoma e chefe do Escritório Regional do Ibama de Bauru, Lélia Lourenço Pinto, por ter me apresentado Ecologia de Estradas e me contaminar com a vontade de trabalhar e fazer mais pelos bichos!;

Ao biólogo e analista ambiental do Ibama de Bauru Thiago Bianconi pela ótimas conversas e incentivo;

Aos queridos França, Ana Ligia, Hosana, Toshiko e Paula que integram a equipe do Ibama de Bauru.

À Rufford Small Grants pela concessão de um prêmio em dinheiro para possibilitar todo o trabalho de campo;

À Neotropical Grassland Conservation pela concessão de um prêmio em equipamentos para realização dos trabalhos de campo;

À CAPES pela bolsa de estudos;

Muito obrigada à todos, por tudo! 


\section{Índice}

\section{Página}

Resumo

$\begin{array}{lr}\text { Abstract } & 3\end{array}$

$\begin{array}{lll}1.0 & \text { Introdução } & 6\end{array}$

$\begin{array}{lll}2.0 & \text { Objetivos } & 27\end{array}$

$\begin{array}{lll}2.1 & \text { Objetivo geral } & 27\end{array}$

$\begin{array}{lll}2.2 & \text { Objetivos específicos } & 27\end{array}$

$\begin{array}{lll}3.0 & \text { Métodos } & 28\end{array}$

3.1 Área de Estudo 28

3.2 Monitoramento das passagens inferiores de fauna 31

3.3 Análise de dados 35

3.4 Análise da paisagem 35

3.5 Avaliação da existência de medidas mitigatórias aos atropelamentos no 36 estado de São Paulo

$\begin{array}{lll}4.0 & \text { Resultados } & 37\end{array}$

4.1 Monitoramento e avaliação das pifs 37

4.2 Análise da paisagem 43

4.3 Avaliação da existência de medidas mitigatórias aos atropelamentos no 48 estado de São Paulo

$\begin{array}{lll}5.0 & \text { Discussão } & 51\end{array}$

6.0 Considerações Finais $\quad 62$

$\begin{array}{lll}7.0 & \text { Referências Bibliográficas } & 64\end{array}$

$\begin{array}{lll}8.0 & \text { Anexo } & 72\end{array}$ 
MONITORAMENTO E AVALIAÇÃO DAS PASSAGENS INFERIORES DE FAUNA PRESENTES NA RODOVIA SP-225 NO MUNICÍPIO DE BROTAS, SÃO PAULO.

Palavras Chaves: conectividade de habitats, ecologia de estradas, mamíferos de médio e grande porte, monitoramento da fauna, passagens de fauna.

\section{Resumo}

A Ecologia de Estradas é um novo campo de conhecimento e surgiu das demandas sobre estudos de impactos ambientais em áreas naturais, com a construção de empreendimentos lineares, como estradas, rodovias e linhas férreas. Sérios problemas ambientais ligados à implantação de estradas e rodovias estão sendo analisados em todo o mundo, como: dispersão de espécies exóticas, alteração do ciclo hidrológico, mudanças microclimáticas, produção de material particulado e ruído, contaminação das águas e do solo, perda de habitat, fragmentação de ambientes naturais e, principalmente, o atropelamento de animais silvestres. Vários estudos vêm sendo desenvolvidos especialmente na América do Norte e Europa e medidas mitigatórias para o atropelamento de animais silvestres, como as passagens de fauna, vêm sendo criadas. Essas estruturas restituem a conectividade entre os fragmentos florestais e matrizes permeáveis e, quando efetivas nas travessias de animais, contempla-se a conservação da biodiversidade e a segurança do usuário. O estado de São Paulo possui 81 passagens de fauna em 14 rodovias diferentes e, numa delas, a SP-225, foi realizado o monitoramento de 10 passagens inferiores de fauna (PIF), distribuídas em $51 \mathrm{~km}$ de extensão. O trecho da rodovia em estudo corta os municípios de Dois Córregos, Brotas e Itirapina. Os objetivos deste trabalho foram comparar a efetividade em travessias de mamíferos de médio e grande porte entre diferentes tipos estruturais de PIF, novas e antigas (presentes antes do licenciamento da duplicação da rodovia), com presença e ausência de água. Três tipos diferentes de PIF foram monitorados: passagens quadradas de concreto, redondas de tubo Armco e um terceiro tipo de grande galeria. Também verificamos a influência da paisagem num entorno de 50 metros (buffers) ao redor das PIFs estudadas. O monitoramento foi realizado por meio de filmagens com câmeras digitais de vídeo e canteiros de pegadas com pó de mármore, durante oito dias por mês, no período de um ano, totalizando um esforço amostral de 96 dias. Foram registradas 800 travessias, sendo que 725 foram exclusivas para mamíferos de médio e grande porte, tendo 16 
diferentes espécies representadas. As espécies que mais utilizaram as passagens foram capivara (Hydrochoerus hydrochaeris), com 435 travessias de indivíduos, seguido de veado catingueiro (Mazama gouazoubira), com 94 indivíduos, e tatu galinha (Dasypus novemcinctus), com 52 indivíduos. Os resultados foram testados através de análises de variância e teste correlação de Spearman. Verificou-se que a presença de água é um fator altamente significativo para a travessia da fauna $\left(X^{2}=236,5 ; p<<0,001\right)$. Não detectamos diferença na efetividade dos três tipos de PIF estudados (ANOVA: $\mathrm{F}=1.43$, $\mathrm{p}=0,255$ ) embora o tipo "grande galeria" tenha contemplado a travessia de 15 espécies diferentes, apresentando, portanto, maior riqueza. O baixo número amostral para PIF do tipo grande galeria impediu o uso de seus resultados em testes estatísticos, porém, uma maior amostragem talvez pudesse mostrar maior sucesso desse tipo de PIF. É possível que passagens redondas e quadradas não tenham diferido no número de travessias por terem em média o mesmo tamanho ( $2 \mathrm{~m} \times 2 \mathrm{~m}$ em PIFs quadradas e $2 \mathrm{~m}$ de diâmetro em PIFs redondas), pois talvez os mamíferos de médio e grande porte não tenham predileção por tipos estruturais específicos entre essas duas PIFs. A análise da paisagem no entorno da rodovia demonstrou que as matrizes mais presentes foram as culturas de laranja e pasto, mas a única espécie que respondeu aos tipos de matrizes foi o gambá (Didelphis albiventris), estando freqüente em passagens circundadas por cana de açúcar e pasto. Analisando a ocorrência das espécies estudadas nas PIFs, verificamos que cachorro do mato (Cerdocyon thous) e tatu (Dasypus novemcinctus) se mostraram relacionados negativamente com a presença de água $(\mathrm{p}=-0,72$ e $\mathrm{p}=-0,62$ respectivamente, teste de Spearman), enquanto que veado, gambá e paca se mostraram relacionados positivamente com a presença de vegetação. É possível relacionar o sucesso de travessias de mamíferos de médio e grande porte com PIFs apresentando água também dentro dos limites da paisagem considerados. Nesse sentido, tivemos 676 travessias em passagens úmidas e 46 travessias em passagens secas. A aplicação prática dessa informação é a possibilidade de modificação de tubos de drenagem fluviais já existentes em rodovias (com dimensão mínima de 1,5 m de diâmetro, ou 1,5 m x 1,5 m para caixas retangulares) para a passagem de fauna, ou a construção de novos tubos adaptados para fauna de médio e grande porte nas rodovias em licenciamento para implantação ou duplicação. 


\title{
MONITORING AND EVALUATION OF THE FAUNA UNDERPASSES \\ LOCATED ON SP-225 HIGHWAY IN THE CITY OF BROTAS, SAO PAULO.
}

Key Words: connectivity of habitats, road ecology, medium and large mammals, fauna monitoring, fauna underpasses.

\begin{abstract}
Road Ecology is a new field of knowledge that emerged from environmental impact studies in natural areas due to the construction of linear developments, such as roads, highways and railways. Serious environmental problems linked to the construction of roads and highways have been analyzed worldwide, such as: dispersion of exotic species, hydrological cycle changes, microclimatic changes, the production of particulate material and noise, water and soil contamination, habitat loss, natural environments fragmentation, and road kill. Many studies have been conducted especially in North America and Europe resulting in mitigation measures such as fauna crossings for the reduction of road kill. These structures restore the connectivity between forests fragments and permeable matrices, the conservation of biodiversity and safety of users is taken into consideration when it is effective for the crossings of animals. Sao Paulo State has 81 fauna crossings in 14 different highways and, in particular, there was monitoring of 10 fauna underpasses, on the SP-225 distributed over $51 \mathrm{~km}$. The section of the highway in the study cuts through the municipalities of Dois Corregos, Brotas and Itirapina. The purpose of this study was to compare the different structural types, new and old (present prior to the highway duplication licensing), with and without the presence of water and their effectiveness on medium and large-sized mammals usage of fauna underpasses. Three different types of fauna underpasses were monitored: square concrete underpass, Armco tube tunnels and a third type of open spam underpass. We also verified the influence of the landscape within 50 meters (buffers) surrounding the fauna underpasses studied.
\end{abstract}


The monitoring was made utilizing digital video recording cameras and marble dust beds track stations, eight days a month, during one year, the sampling totaling 96 days. There were 800 crossings registered, 725 were exclusively for medium and largesized mammals, representing 16 different species. The species that most used the crossings were the capybara (Hydrochoerus hydrochaeris), 435 crossings of the individuals, followed by the gray brocket deer (Mazama gouazoubira), with 94 individuals, and the nine-banded armadillo (Dasypus novemcinctus ), with 52 individuals. The results were tested through the analysis of variance and Spearman correlation test. It was found that the presence of water is a highly significant factor for the fauna crossing $\left(X^{2}=236,5 ; \mathrm{p}<<0,001\right)$. We detected no difference in the effectiveness of the three types of underpasses studied (ANOVA: $F=1.43, p=0,255$ ) although the type "open spam underpass" demonstrated greater diversity with the crossings of 15 different species. The low sampling number for the type of open spam underpass prevented the usage of the results in statistical tests; however a larger sampling would probably be able to show a greater success of this type of fauna underpass structure. It is possible that there had not been a difference in the number of crossings in round culverts and square culverts because these structures have on average the same size $(2 \mathrm{~m} \times 2 \mathrm{~m}$ in square underpasses and $2 \mathrm{~m}$ in diameter in round underpasses). Maybe because medium and large-sized mammals don't have a preference for specific structural types between these two types of fauna underpasses. The analysis of the landscape in the surrounding areas of the highway showed that the cultures of orange and pasture were the prevalent matrices, but the white-eared opossum (Didelphis albiventris) was the only specie that responded to these types of matrices. The white-eared opossum was found frequently in landscapes surrounded by sugar cane and pasture. Analyzing the occurrence of the species studied in the fauna underpasses, we verified that crab eating fox and armadillo demonstrated a negative interaction with water $(p=-0,72$ e $p=-0,62$ respectively, Spearman test), whereas gray brocket, white eared opossum and spotted paca demonstrated a positive interaction with the presence of vegetation 
It is possible to relate the success of the crossings of medium and large-sized mammals with fauna underpasses to the presence of water within the limits of the landscape considered. Hence, there were 676 crossings in wet landscapes and 46 crossings in dry landscapes. The practical application of this information is the possibility of modification of the water drainage pipes already existing in the highways (with minimum dimension of $1.5 \mathrm{~m}$ in diameter, or $1.5 \mathrm{~m} \mathrm{x} 1.5 \mathrm{~m}$ for rectangular boxes) for fauna crossing, or that the construction of new pipes adapted for medium and largesized fauna be required in highways that are in the licensing process for implantation or duplication. 


\section{Introdução}

\section{O surgimento de uma nova disciplina}

O desenvolvimento urbano e a construção de ferrovias, rodovias e estradas - chamados empreendimentos linearesde infraestrutura de transporte estão entre as alterações ambientais que causaram os maiores impactos nas paisagens naturais no século XX em todo o mundo, incluindo grandes mudanças nas populações animais (Lodé, 2000; Bergallo et al., 2001; Bond \& Jones, 2008). Em geral, os projetos viários são considerados obras que representam benefícios sociais e econômicos para as regiões e melhoram a qualidade de vida dos habitantes, constituindo assim um elemento importante de desenvolvimento (Cain et al, 2003; Arroyave \& Gómez, 2006). No imaginário popular, as rodovias estão associadas à idéia de progresso e modernidade e, há algumas décadas atrás, não se fazia qualquer menção a nenhum aspecto ambiental negativo dessas construções e, tampouco, durante sua operação (Prada, 2004). No entanto, a construção de novas rodovias, particularmente intensa no último século nos países desenvolvidos e em desenvolvimento, permitiu a expansão da rede viária até as mais remotas áreas naturais remanescentes, resultando muitas vezes na quebra de conectividadedas relações ecológicas nos ecossistemas por elas cortados (Trocmé, 2006).

A maior conscientização sobre os danos das ações humanas ao meio ambiente e a busca de formas mais racionais de uso dos recursos fortaleceu-se a partir dos anos de 1970-80, nos países desenvolvidos, e seguiu-se no restante do mundo em desenvolvimento. As exigências de estudos sobre os impactos 
causados por grandes obras, dentre elas, as rodovias, abriu um novo campo de estudo, a Ecologia de Estradas. Essa nova área de conhecimento da Ecologia, que apresenta como propósito explorar a ampla relação entre o ambiente natural e o sistema rodoviário,firmou-se como uma disciplina a partir de 2003, quando foi publicado o livro "Road Ecology: Science and Solutions", de Richard Forman (Beckmann, et al., 2010).

O nome "Ecologia de Estradas" é a tradução exata do inglês Road Ecology. Entretanto, o Código Brasileiro de Trânsito (CTB, 2006) diferencia "estrada" de "rodovia". Estrada é classificada como uma via rural sem pavimentação, enquanto que a rodovia é necessariamente uma via rural pavimentada. Dessa forma, o termo "rodovia" seria mais bem empregado para tratar das vias principais e secundárias nos âmbitos municipal, estadual e federal, e é com base nessas rodovias que os estudos sobre atropelamento de fauna silvestre e implantação e monitoramento de passagens de fauna são realizados.

A Ecologia de Estradas tem como base a Ecologia de Paisagens, uma vez que tenta integrar as estradas e rodovias- estruturas lineares - à paisagem em que se insere. Assim, a distribuição espacial dos fragmentos de ecossistemas naturais ou antropizados, a conectividade entre eles e a qualidade da matriz circundante são questões fundamentais a serem consideradas na concepção de estradas e rodovias para que causem menos empecilhos principalmente à locomoção da fauna local.

Os elementos básicos de uma paisagem fragmentada são as manchas de habitat ou não-habitat, a matriz e os corredores. As manchas são definidas como áreas homogêneas de uma unidade da paisagem (numa determinada escala) que se distingue das unidades vizinhas e apresenta extensões espaciais reduzidas e 
não lineares; já os fragmentos são manchas relativamente isoladas de habitat, originadas pelo processo de fragmentação, geralmente promovida pelo homem, de áreas que inicialmente se apresentavam contínuas, (Metzger, 1999).

A matriz é uma área heterogênea, contendo uma grande variedade de unidades de não-habitat que apresentam condições mais ou menos favoráveis às espécies do habitat estudado. Em regiões tropicais antropizadas, a matriz geralmente é composta de áreas agrícolas e pastagens (Metzger, 1999). Matrizes são responsáveis em determinar, em grande parte, o grau de isolamento das populações nativas nas manchas de vegetação, pois a movimentação da fauna dependerá de quão abruptas são as diferenças entre a matriz e as porções de habitat isolados. A fauna que coloniza a matriz geralmente apresenta adaptações especiais e amplos limites de tolerância (Gascon et al, 1999).

Ainda, corredores são definidos como áreas homogêneas de uma unidade da paisagem que se distinguem das unidades vizinhas e que apresentam disposição espacial linear (Metzger, 1999). Eles têm sido utilizados como estratégias para mitigar os efeitos da fragmentação e promover a conservação da biodiversidade desde o início do século XX (Hess \& Fischer, 2001).

Os corredores podem ser descritos de acordo com as suas funções ambientais, quais sejam: i) habitat - o corredor é uma área apropriada de recursos (alimento, abrigo) e condições ambientais para reprodução e sobrevivência das espécies; ii) condutor - quando promove ou aumenta a capacidade dos animais de se moverem entre as manchas de habitat; iii) filtro e barreira - o termo "filtro" implica em algum nível de permeabilidade e geralmente está associado a zonas ripárias, o termo "barreira" implica em impedir, bloquear o fluxo, o que comumente ocorre com a fauna em estradas e 
rodovias; iv) fonte e sumidouro - no primeiro caso, o corredor tem a capacidade de prover animais na paisagem, enquanto que no corredor sumidouro, os organismos desaparecem, devido a ampla exposição dos animais na borda, deixando-os suscetíveis aos predadores residentes nas matrizes ou então pela competição entre espécies generalistas (Hess \& Fischer, 2001).

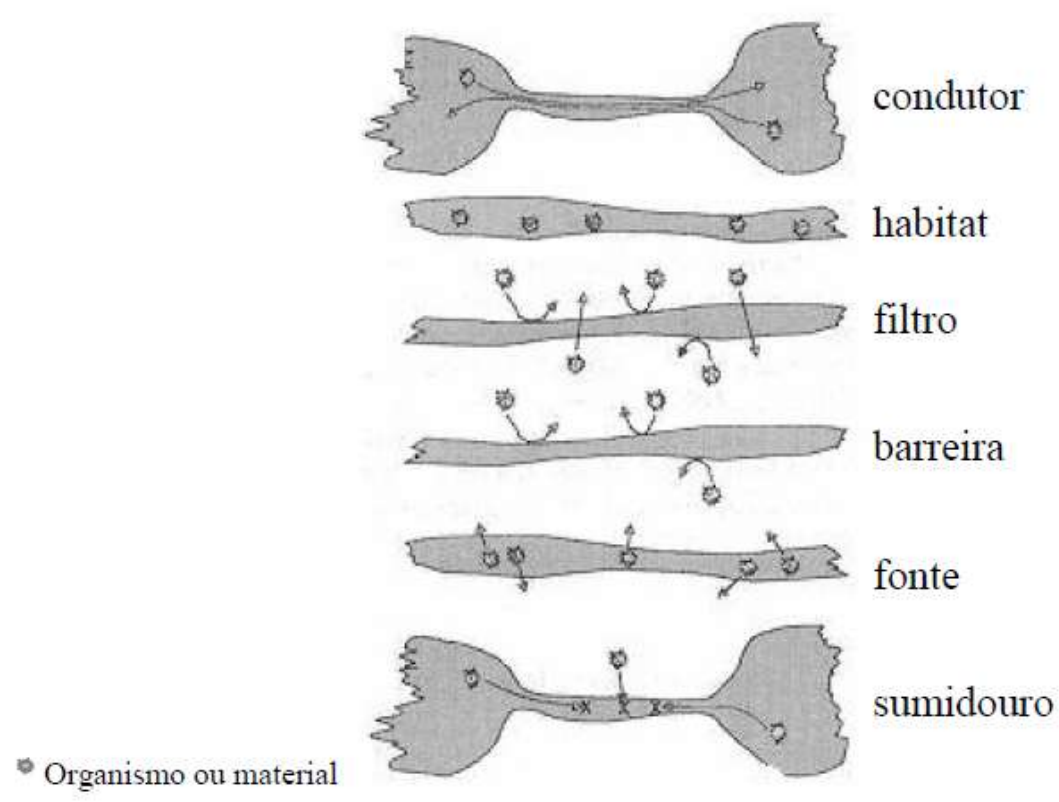

Figura 1 - Principais tipos de corredores e representação da dinâmica de deslocamento dos organismos por meio deles (Adaptado de Hess \& Fischer, 2001).

A Ecologia de Paisagens tem suas bases a partir de duas teorias ecológicas principais: a da Biogeografia de Ilhas e a de Metapopulações, que enfatizam a importância da conectividade na paisagem. A teoria da Biogeografia de Ilhas foi elaborada para procurar explicar a dinâmica da riqueza e composição de espécies em ilhas de diferentes tamanhos e diferentes distâncias do continente (MacArthur \& Wilson, 1967). Mais tarde, essa teoria passou a ser aplicada também em paisagens terrestres, fazendo-se analogia entre as ilhas e manchas de habitats terrestres, e sendo o oceano representado pelos habitats desfavoráveis. 
Fragmentos altamente isolados ou muito pequenos, de acordo com essa teoria, conteriam menos espécies do que manchas maiores ou altamente conectadas. A teoria de Biogeografia de Ilhas em sistemas terrestres foi posteriormente aprimorada, incorporando-se noções sobre a qualidade das manchas de habitat e considerando-se a possibilidade da existência de fluxos de indivíduos entre todos os fragmentos da paisagem. Surgiu, então, a teoria de Metapopulações, que visava explicar como diferentes níveis de conectividade numa população de uma determinada espécie num determinado local afetariam a persistência da população inteira em longo prazo (Gilpin \& Hanski, 1991).

A teoria de Metapopulações tem o seu enfoque no intercâmbio de indivíduos entre populações espacialmente distribuídas. Metapopulação pode ser definida como um conjunto de sub-populações de organismos (populações vizinhas), existindo ao mesmo tempo e ocupando, cada uma, áreas diferentes e relativamente próximas. Algumas dessas populações estariam em declínio, extinguindo-se local e temporalmente, enquanto outras estariam aumentando demograficamente, realimentando as primeiras. Essa teoria foi concebida para descrever e predizer a dinâmica de populações de espécies ocupando naturalmente fragmentos de habitats e sugere que, aumentando-se a conectividade estrutural e funcional na paisagem, aumentam as chances de acesso aos recursos necessários às espécies, a recolonização de manchas onde populações foram localmente extintas e a manutenção da diversidade genética (Beckmann et. al., 2010). Essa teoria enfatiza, portanto, que a conectividade é um componente-chave para a conservação da biodiversidade. Populações conectadas geralmente apresentam maior probabilidade de sobrevivência e uma 
maior flexibilidade em responder às mudanças das condições ambientais e distúrbios naturais (Beckmann et. al., 2010).

A conectividade depende da proximidade dos elementos do habitat, da densidade dos corredores e da permeabilidade da matriz e pode ser classificada como conectividade estrutural ou funcional. A conectividade estrutural relaciona-se ao arranjo espacial dos fragmentos, densidade ou complexidade dos corredores e permeabilidade da matriz (Metzger, 2001). Por outro lado, a conectividade funcional é avaliada pelos fluxos de disseminação ou pela intensidade de movimento inter- habitat dos organismos (Metzger, 1999).

\section{Impactos causados por estradas e rodovias}

A Ecologia de Estradas possui duas faces relevantes e dependentes para estudos e aplicações: a segurança dos usuários nas rodovias e a conservação da biodiversidade, que diz respeito à mortalidade de animais silvestres por atropelamento (Beckmann et al., 2010). Esse tipo de enfoque foi dado em muitos trabalhos realizados na América do Norte, e compilados no livro Safe Passages - highways, wildlifeand habitat connectivity, publicado por Jon P. Beckman e colaboradores (Beckmann et al., 2010). Em 2007, por exemplo, quase dois milhões de acidentes envolvendo veículos automotores e mamíferos de grande porte foram contabilizados nos Estados Unidos, causando um prejuízo da ordem de US\$ 8,3 bilhões (Huijseret al., 2007). Na França, a média de pessoas mortas em acidentes envolvendo ungulados é de aproximadamente 50 por ano, além de quase 2500 pessoas feridas nesse tipo de colisão (Bruinderink \& Hazebroek, 1996). 
Estima-se que, diariamente, um milhão de vertebrados são mortos por atropelamento nas rodovias dos Estados Unidos (Forman \& Alexander, 1998; Beckmann et al., 2010). Os carnívoros mais atropelados nesse país são os de maior porte, como: urso pardo (Ursus arctos), urso preto (Ursus americanus), lobo cinzento (Canis lupus), puma (Puma concolor), lince (Lynx sp), além de pequenos felinos (Hass, 2000; Graves et al., 2006).

Nos países da Europa, a morte de animais por atropelamento também tem sido identificada como uma das principais ameaças à vida selvagem (Tabela1) (Trocmé, 2006). Na Suíça, por exemplo, o atropelamento é responsável por $23 \%$ da mortalidade do lince europeu (Lynx pardinus), espécie atualmente com o status de criticamente em perigo segundo a IUCN Red List of threatened species. (International Union for Conservartion of Nature) (IUCN - Red List, 2012)

Tabela 1 - Espécies de médios e grandes mamíferos selvagens mais ameaçados por atropelamentos em rodovias nos países da Europa.

\begin{tabular}{|c|c|c|}
\hline País & Espécies atingidas & Autor (es) \\
\hline Alemanha & Lontra (Lutra lutra) & Hauer et al., 2002 \\
\hline Espanha & furão (Mustela putorius) & $\begin{array}{c}\text { Barrientos \& Bolonio, } \\
2008\end{array}$ \\
\hline França & geneta (Genetta genetta) & Lodé, 2000 \\
\hline & texugo (Meles meles), lontra & Clarke et al., 1998; \\
\hline Inglaterra & (Lutra lutra), raposa & Kruuk \& Conroy, 1991; \\
\hline & vermelha (Vulpes vulpes) & Baker et al., 2004 \\
\hline Israel & lontra (Lutra lutra) & Guter et al.,2005 \\
\hline Itália & $\begin{array}{l}\text { urso cinza (Ursus arctos), } \\
\text { lobo (Canis lupus) }\end{array}$ & $\begin{array}{l}\text { Lovari et al., 2007; } \\
\text { Falcucci et al.,2009 }\end{array}$ \\
\hline Noruega & cervo (Cervus elaphus) & Misterud, 2004 \\
\hline Noruega & ursocinza (Ursus arctos) & Kaczensky et al., 2003 \\
\hline
\end{tabular}


Portugal

Suécia
Geneta (Genetta genetta), texugo (Meles meles)

alce (Alces alces)
Brito \& Alvares, 2004;

Gomes et al., 2008;

Grilo et al., 2009

Seiler, 2005

Além do atropelamento de fauna, existem outros impactos negativos causados por rodovias, que incidem diretamente sobre a integridade biótica e causam danos ecológicos significativos. Alguns deles são: i) facilitação da dispersão de espécies exóticas por meio dos corredores lineares formados pelas rodovias; ii) alterações de ciclos hidrológicos devido a interrupções na drenagem, causadas pela construção de rodovias; iii) mudanças microclimáticas devido à pavimentação - a qual tende a aumentar as temperaturas locais e diminuir a umidade do ar; iv) poluição atmosférica devida à produção de gases tóxicos e material particulado liberados pelos veículos; v) produção de ruído pelos veículos; vi) contaminação das águas e do solo por substâncias liberadas pelos veículos; vii) perda e degradação de habitats, viii) fragmentação de ambientes naturais (Forman \& Alexander, 1998; Trombulak \& Frissell, 2000; Forman et. al.,, 2003; Iuell e. al., 2003; Arroyave \& Gómez, 2006, Goosem, 2007).

Da mesma forma, as rodovias causam impactos ambientais indiretos nos padrões e processos ecológicos, como efeitos de barreira para a fauna silvestre e a perda de conectividade entre ambientes naturais (Bissonete \& Adair, 2008).

Para as espécies nativas, a quebra de conectividade entre os remanescentes naturais é uma grande ameaça, acarretando em problemas no fluxo gênico e declínio populacional regional (Iuell, 2003; Taylor \& Goldingay, 2004; MMA, 2005). Em casos onde a conectividade deve ser restabelecida, é 
necessário que sejam implantados corredores, como as passagens de fauna. Essas estruturas têm como princípio restabelecer a conectividade estrutural entre paisagens, bem como a conectividade funcional. O grande desafio é projetar passagens adequadas para que elas não sejamsimplesmente estruturas que conectem os ambientes estruturalmente, mas também funcionalmente, o que pode ser mensurado pelo número de travessias.

Além dos impactos negativos apontados, as rodovias também podem resultar em impactos positivos para algumas espécies, como para o alce (Alces alces), observado no Parque Nacional "Grand Teton" nos Estados Unidos, onde se constatou que algumas fêmeas dão àluz seus filhotes muito próximos às rodovias. Uma possível explicação para esse comportamento é a menor atividade de um dos maiores predadores de alces, o urso pardo (Ursus arctos), em áreas próximas às rodovias. Dessa forma, a permanência das crias próximas a estradas aumentaria a chance de sobrevivência dos filhotes, evitando ataques do urso pardo (Berger, 2007).

\section{Ecologia de Estradas promovendo a conectividade}

Uma vez que a conectividade é considerada um elemento vital na estrutura da paisagem para a sobrevivência de populações animais e vegetais porque promove o fluxo das espécies na paisagem (Godwin \& Fahrig, 2002), a Ecologia de Estradas busca formas de manter ou restaurar a conectividade especificamente para a fauna afetada pela construção de rodovias.

A construção de estruturas que aumentem a permeabilidade da paisagem, ou seja, estruturas que possibilitem a movimentação da fauna silvestre entre fragmentos de habitat, mesmo que isolados, pode aumentar ou manter os níveis 
de dispersão, além de possibilitar fluxo genético e promovera viabilidade da população de espécies-alvo (Corlatti, et al.,2009). Do ponto de vista genético, a eficácia de estruturas de mitigação, como as passagens de fauna, para evitar atropelamentos é definida por sua habilidade em restabelecer o fluxo entre populações selvagens e, assim, garantir a viabilidade populacional das espécies prejudicadas pela fragmentação (Corlatti et al., 2009).

Uma das maneiras mais simples e efetivas para restabelecer essa conectividade é a construção de passagens de fauna. É desejável que sejam favorecidos, com essas passagens, diferentes grupos faunísticos e um maior número de espécies. Assim, não apenas o tipo de passagem, mas a escala de conectividade abrangida deve ser considerada. Certas espécies, como o carcaju (Gulo gulo), necessitam de conectividade em escalas continentais, enquanto que outras espécies, como o alce (Alces alces), necessitam de corredores em locais específicos (Beckmann et. al., 2010).

Atualmente, biólogos, engenheiros e arquitetos têm trabalhado em conjunto na implantação de medidas mitigadoras em rodovias. A escolha do tipo de passagem de fauna mais apropriada deve contemplar a paisagem, o tipo de habitat afetado e as espécies- alvo. As propostas de mitigação de atropelamentos de fauna baseiam-se na implementação de mecanismos como: refletores, que com a luz dos veículos se ilumina e fica em destaque para a percepção da fauna próxima à rodovia (Sielecki, 2001; D’angelo et al., 2006), placas de sinalização para os usuários para que se atentem às possíveis travessias de fauna, diminuição da velocidade e outras informações (Clevenger \& Waltho, 2003; Ascensão \& Mira, 2006) e estruturas construídas especificamente para a travessia de fauna, 
que se apresentam subterrâneas ou aéreas, sempre acompanhadas de cercas-guia (Griloet al., 2008).

Diversos estudos relativos ao atropelamento de animais em rodovias, efetuados na Europa e América do Norte, permitiram a implantação de passagens de fauna para diferentes espécies de vertebrados (Lodé, 2000; Clevenger \& Waltho, 2003; Taylor \& Goldingay, 2004; Clevenger \& Waltho, 2005; Bond \& Jones, 2008; Corlatti et al, 2009), diminuindo, assim, as mortes por atropelamento.

As passagens de fauna devem ser empregadas juntamente com as cercas condutoras, pois as duas estruturas são parte de um conceito único para manter a conectividade entre populações de animais. Na tentativa dos animais atravessarem as rodovias, eles são primeiramente barrados pelas cercas, que funcionam como guias para conduzi-los até as passagens de fauna. Sem as cercas, o sucesso das passagens é baixíssimo (Iuell, 2003; Trocmé, 2006).

De modo geral, o modelo e o tamanho dessas passagens podem variar e isso reflete no sucesso de travessia para diferentes grupos faunísticos (Trocmé, 2006). Dentre as passagens subterrâneas, destacam-se:

- galerias: são classificadas entre as passagens de uso misto, visando facilitar ou possibilitar a travessia a grupos faunísticos aquáticos, semi-aquáticos ou espécies que se desloquem acompanhando cursos d’água (Figura 2) (Beckmann et al., 2010). 


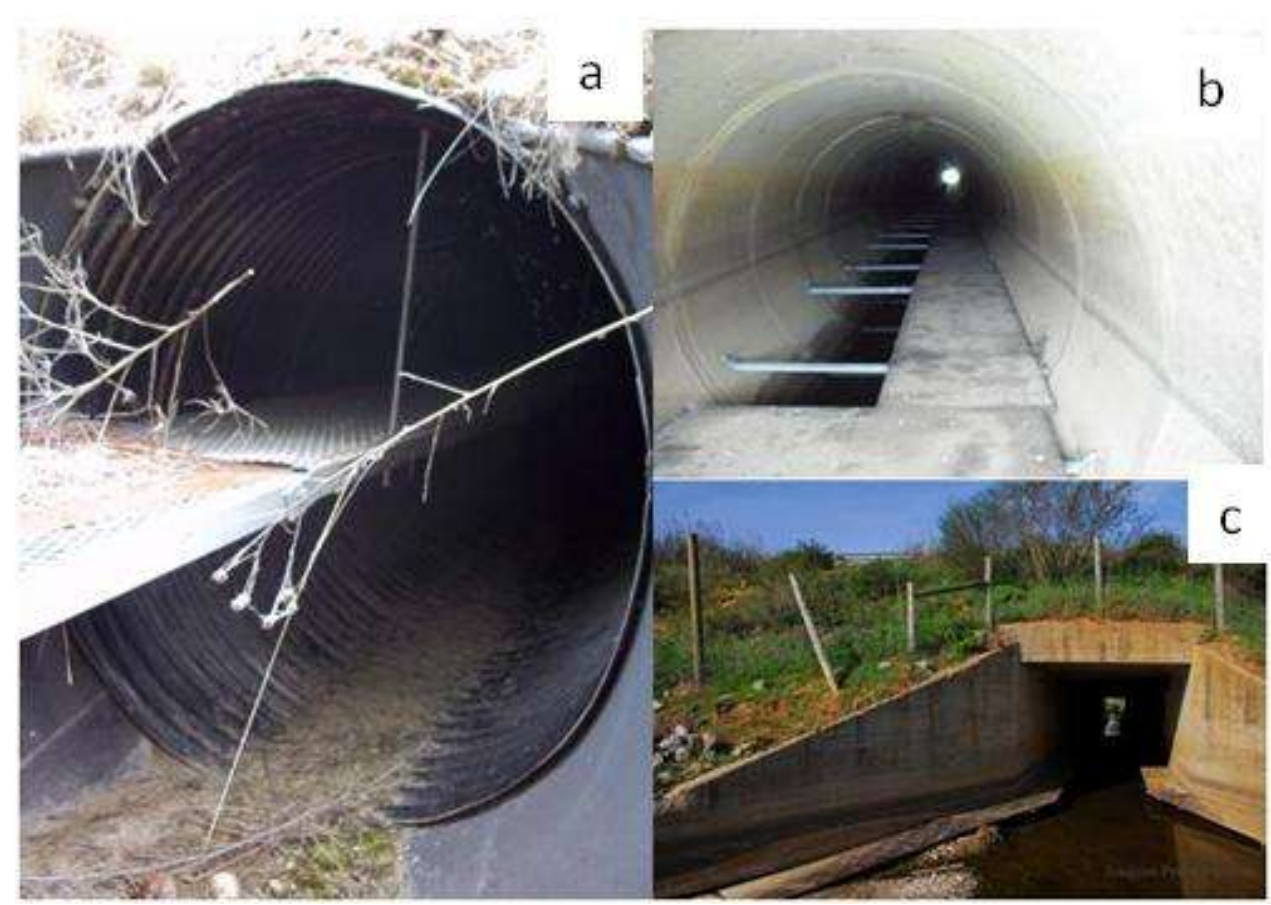

Figura 2: Exemplos de passagens de fauna do tipo galerias: (a) galeria metálica redonda, com passarela metálica suspensa, em Montana (EUA), (b) galeria de concreto redonda, com passarela adaptada para estação chuvosa, no Alentejo (Portugal), (c) galeria de concreto quadrada, com passarela permanente em ambos os lados da passagem, no Alentejo (Portugal). (Foto: Fernanda Delborgo Abra.)

No passado, essas estruturas não eram planejadas para contemplar a travessia de fauna (Peris \& Morales, 2004), sendo o uso principal para drenagem de águas pluviais ou fluviais, mas vários estudos apontaram grande sucesso no seu uso por animais silvestres de pequeno e médio portes, em rodovias do Alentejo (Portugal), Madri, Orense (Espanha), Califórnia, Flórida, Texas, Montana (Estados Unidos) e Alberta (Canadá) (Yanes et al., 1995; Boarman et al., 1997; Rodríguez et al., 1997; Clevenger et al., 2001; Cainet al., 2003; Dodd Jr et al., 2004; Ng, et al., 2004; Ascensão\& Mira, 2006; Trocmé, 2006, Mata et al., 2007).

Atualmente, as galerias têm sido modificadas em suas estruturas para permitir seu uso por diferentes espécies. Assim, muitas galerias apresentam muretas laterais ou pranchas secas suspensas em seu interior para que espécies 
da fauna que não se locomovem naágua ou pequenos mamíferos também possam utilizá-las (Clevenger et al., 2001).

- caixas secas: constituem um tipo de estrutura a ser instalado em ambientes secos e visam à travessia de animais que não se deslocam por água ou em ambientes úmidos (Figura 3). Essas passagens se apresentam de forma quadrada e de concreto, mas podem ser planejadas e construídas em diversos tamanhos, conforme características das espécies-alvo ou visando certos grupos faunísticos.

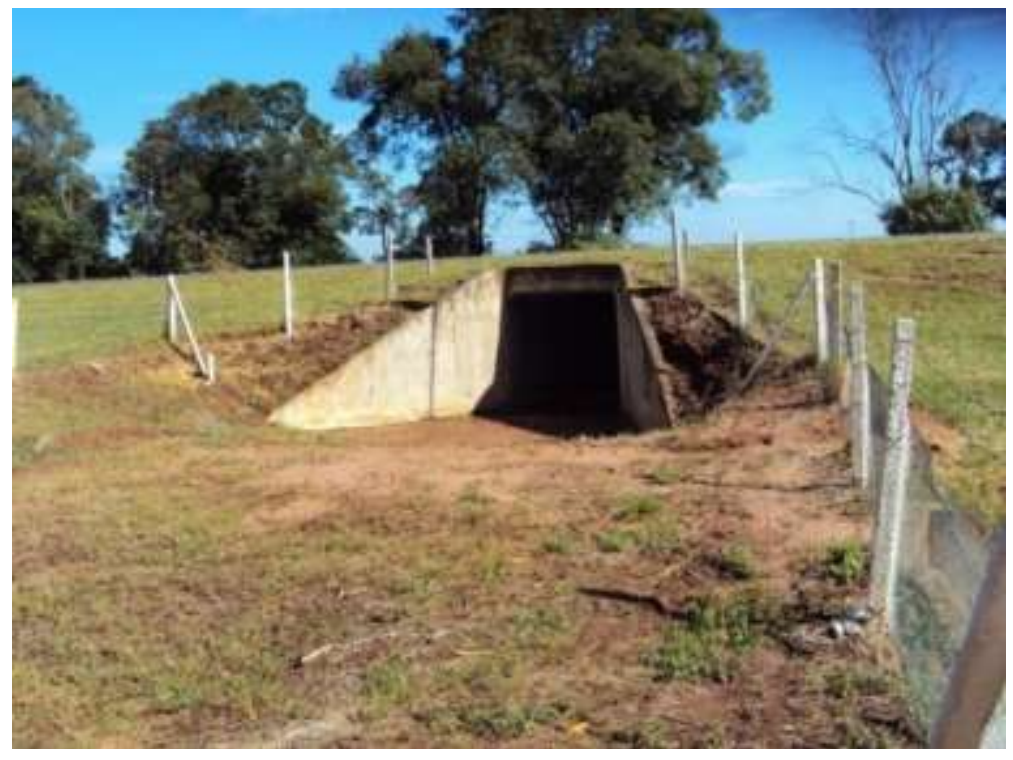

Figura 3: Passagem de fauna do tipo caixa seca, acompanhada de cerca condutora, na rodovia SP-225, em Brotas, Brasil.(Foto: Fernanda Delborgo Abra)

As caixas secas têm sido empregadas em vários lugares do mundo, como Boxtel e Eindhoven (Holanda), Zamora e Orense (Espanha), Alentejo (Portugal), Alberta (Canadá), Montana (Estados Unidos) e Hungria. Alguns autores notaram grande eficiência no seu uso por animais quando estão associadas às galerias mistas (Foster \& Humphrey, 1997; McDonald \& Clair, 2004; Ng, et al., 2004; Clevenger \& Waltho, 2005; Mata et al., 2005; Van Vuurde \& Van Der Grift, 2005; Beckmann et al., 2010).

Dentre as passagens aéreas, destacam-se: 
- passagem aérea para vertebrados arborícolas: esse tipo de passagem é destinado a conectar habitats florestais separados por rodovias (Figura 4). Essas passagens contemplam grupos faunísticos arbóreos e semi-arbóreos, como primatas e marsupiais. Poucas estruturas desse tipo foram construídas até hoje, majoritariamente sendo encontradas na Austrália (Queensland) e algumas iniciativas foram tomadas em Madagáscar (Moramanga) e Brasil (São Paulo, Rio Grande do Sul e Espírito Santo) (Goosem, 2004; Lockscin et. al., 2007; Mass et al., 2011).

Na Avenida Miguel Stefano (São Paulo, SP), ao lado da Fundação Parque Zoológico Municipal de São Paulo e inserido no Parque Estadual Fontes do Ipiranga, foi instalada, há cerca de três anos, uma passagem aérea para primatas, mas não é sabido o sucesso do uso dessa estrutura pelos animais (Artesp, 2011).

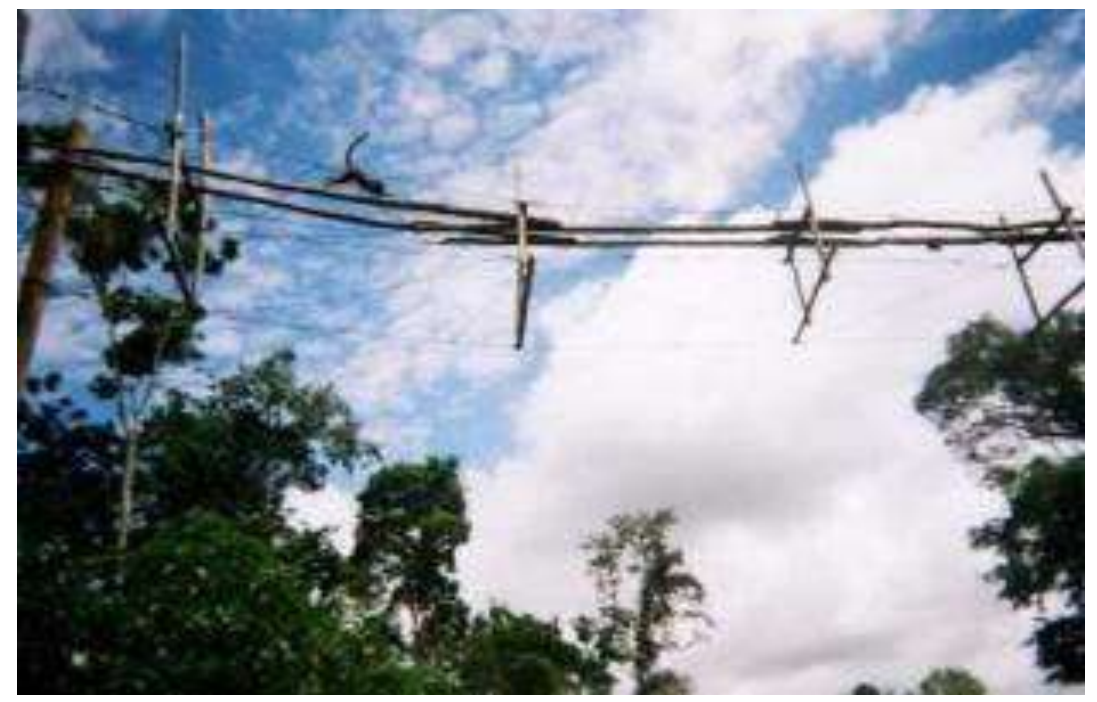

Figura 4: Eulemurfulvus utilizando passagem de fauna aérea construídas com madeiras e cordas em Moramanga (Madagáscar) (Masset al., 2011). (Foto: Masset al., 2011)

Esse tipo de passagem consiste em unir as copas das árvores separadas pela rodovia por meio de cordas, bambus e canos, sendo amarrados ou afixados nas árvores ou postes de iluminação (Goosem, 2004, Beckmann et. al., 2010). 
- viaduto de fauna: são estruturas cujo objetivo é re-conectar a paisagem e promover o fluxo da fauna silvestre entre fragmentos cortados por rodovias de múltiplas faixas (Figura 5). A largura desse tipo de estrutura, implantada em vários países da Europa e América do Norte, variam de 40 a100 metros (Beckmann et al, 2010).

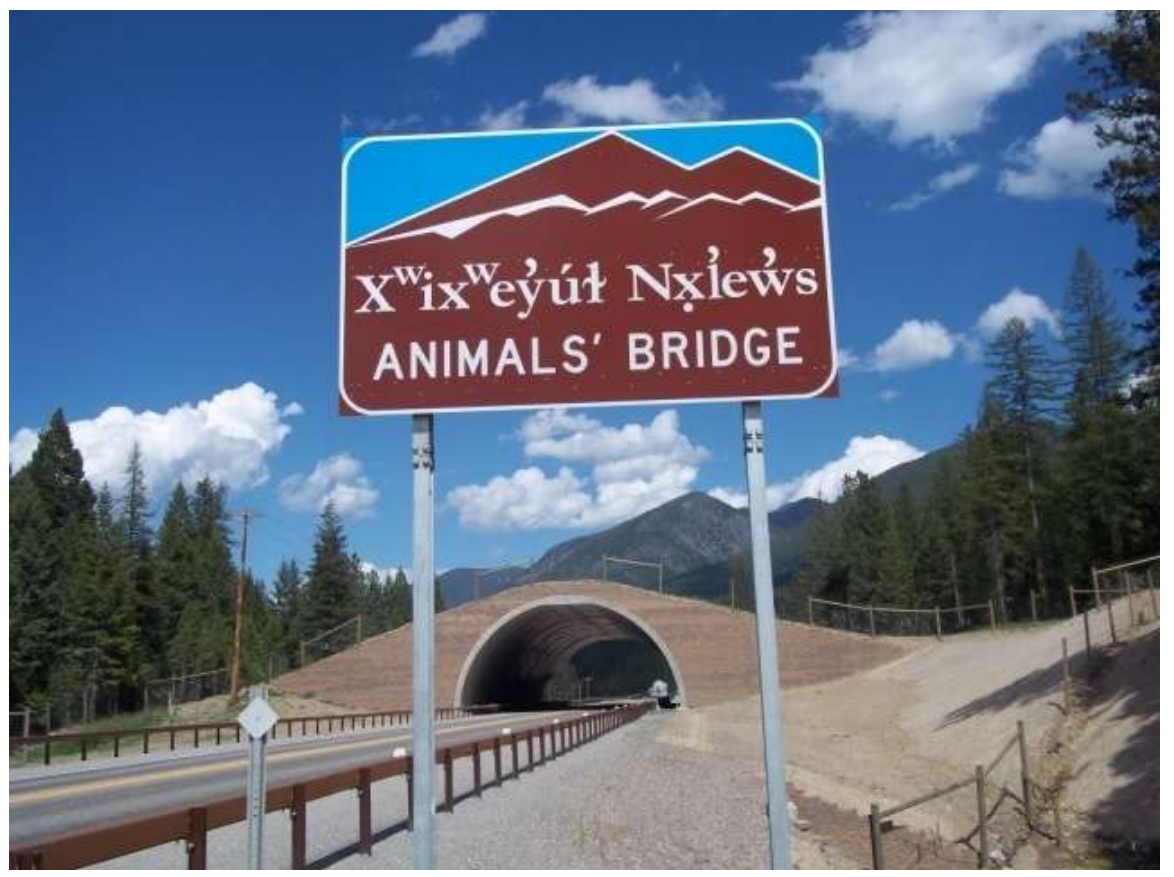

Figura 5: Viaduto de fauna na Highway 93, em Montana, Estados Unidos. A placa de sinalização indica a passagem de fauna aos condutores na língua inglesa e indígena, uma vez que a rodovia corta uma área indígena da tribo Salish Kootenai.(Foto: Fernanda Delborgo Abra)

Estudos apontam que os viadutos de fauna privilegiam a travessia de mamíferos de grande porte, como veados (Odocoileus virginianus, Odocoileus hemionu), alces (Alces alces) e ursos (Ursus arctus, Ursos americanos), porém, animais de pequeno e médio porte também podem utilizá-los, caso apresentem terreno e vegetação adequados (Beckmann et al, 2010).

A França foi o primeiro país a adotar os viadutos de fauna, na década de 1960. Nesta mesma década, outros viadutos de fauna foram construídos em Luxemburgo e Holanda, a pedido de caçadores, que perceberam que as rodovias 
impediam o fluxo de cervos entre as áreas de caça. Assim, a implantação de viadutos de fauna é bem difundida na Europa, havendo registros na Itália, Espanha, Croácia, Alemanha, Suíça, Holanda, Austrália, Hungria, República Tcheca, Suécia e Noruega (McDonald \& Clair, 2004; Iuell et al., 2003; Mata et al., 2005, Mata et al., 2007, Olsson et al., 2008), mas também têm sido implantados nos Estados Unidos, Canadá e Austrália (Beckman et al, 2010).

O primeiro viaduto de fauna construído nos Estados Unidos foi em 2000, na Flórida, e outros têm sido construídos no Havaí, Nova Jersey, Utah, Montana e Connecticut. No Canadá, existem dois viadutos de fauna no Banf National Park, em Alberta (Evink, 2002; Bond \& Jones, 2008).

Além das passagens de fauna, subterrâneas e aéreas, as cercas e elevados também são consideradas estruturas de mitigação:

- elevados: esse tipo de estrutura é a maior estrutura de mitigação para rodovias de múltiplas faixas (Figura 6). São construídas acima do dossel da mata nativa por onde a rodovia será traçada, com a finalidade de não danificar ou fragmentar a vegetação natural, e podem funcionar como uma passagem de uso misto quando há corpos d’agua embaixo da rodovia. Por apresentarem grande extensão, largura e altura, constituem uma medida mitigadora para travessia de fauna por baixo da estrutura que contempla vários grupos, como mamíferos, anfíbios, répteis, aves e até invertebrados (Forman et al., 2003). 


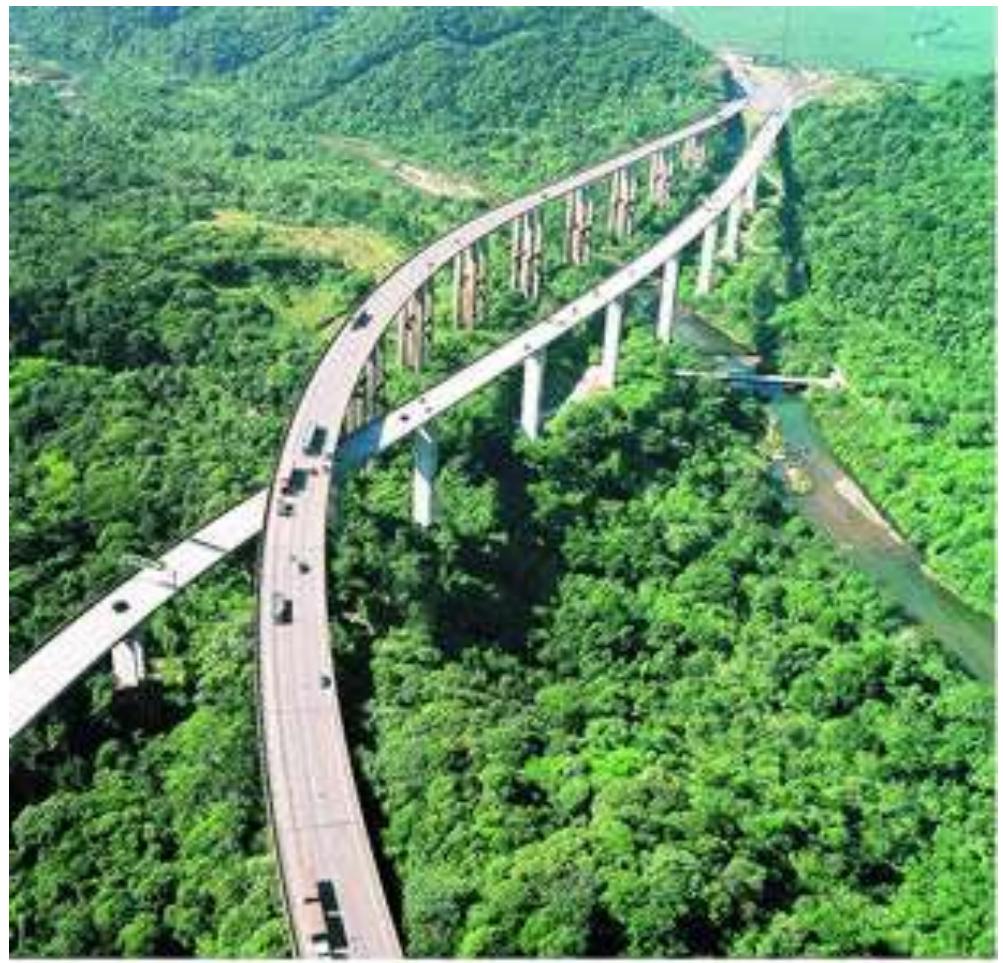

Figura 6: Elevado na SP-160, Rodovia dos Imigrantes, em São Paulo, Brasil.(ECOVIAS, 2011). (Foto: Ecovias.)

Esse tipo de estrutura geralmente é implantado em áreas protegidas e com alta diversidade biológica, mas, por apresentarem um custo alto para implantação, os elevados são pouco utilizados. Essas obras estão presentes em poucos lugares do mundo, como: Cantão de Bern (Suíça), Zamora, Palência e Montes de Toledo (Espanha), Flórida e Arizona (Estados Unidos (Foster \& Humphrey, 1997; Dood et al.,2004; Ng, et al., 2004; Peris \& Morales, 2004; Mata et al., 2005; Trocmé, 2006).

-cercas ou alambrados de condução: as cercas (Figura 7) foram dos primeiros tipos de estruturas de mitigação para fauna implantadas em vários países da Europa, como na Suíça (Trocmé, 2006) e na América do Norte no Canadá e Estados Unidos (Beckman, et al., 2010) a fim de conter a entrada de animais nas rodovias, visando primeiramente à segurança do usuário. 
Os tamanhos das cercas variam em diferentes países, de acordo com a fauna local cuja entrada na rodoviase objetiva barrar econduzir até uma passagem de fauna (Beckmann, et. al., 2010).

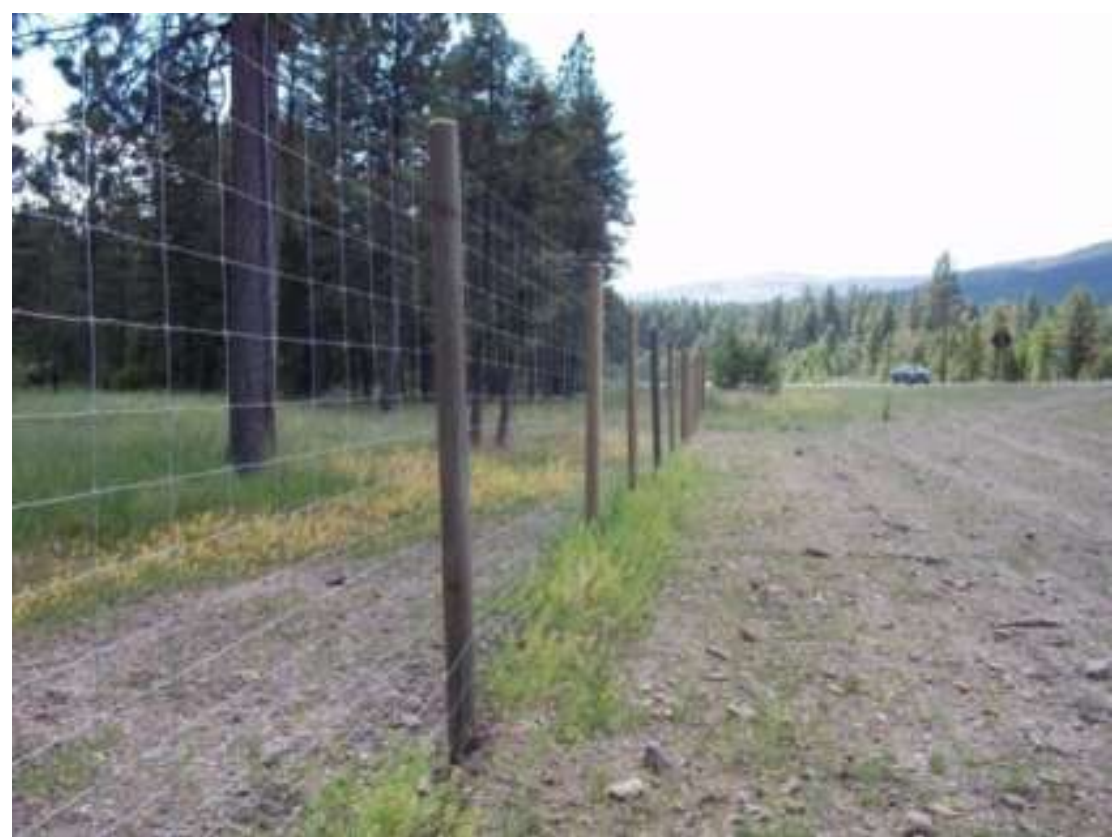

Figura 7: Cerca de condução na Highway 93, no Estado de Montana, Estados Unidos. (Foto: Fernanda Delborgo Abra).

Hoje, o consenso entre especialistas do mundo todo é que cercas só podem ser implantadas em rodovias quando associadas às passagens de fauna, caso contrário, causam um efeito de barreira, impedindo o fluxo de indivíduos e, portanto, o fluxo gênico entre a fauna silvestre, podendo ocasionar extinções locais (Beckmann et al., 2010).

As autoridades necessitam urgentemente de métodos para prever, avaliar e mitigar efeitos adversos das estradas e rodovias, e utilizar esse conhecimento no planejamento e manutenção da infra-estrutura de transportes (Seiler, 2003).

Nos anos de 2007 a 2010, o Programa de Aceleração ao Crescimento (PAC) implantou $45.337 \mathrm{~km}$ de obras rodoviárias no Brasil, dentre as quais, obras de recuperação, adequação, duplicação e construção de novas rodovias, 
que custaram 33,4 bilhões de reais ao governo brasileiro. O PAC-2, assim chamado por ser a segunda versão do programa federal, prevê, nos anos de 2010 a2014, a destinação de mais 33,4 bilhões de reais para consolidar e ampliar a rede rodoviária do país, sendo que, em outras estruturas de transporte como as ferrovias, serão aplicados 7,9 bilhões e somente 700 milhões deverão ser investidos em obras hidroviárias (PAC, 2011). É, portanto, necessária e urgente a criação de um embasamento científico nacional para que tais obras alcancem também as metas para a conservação da biodiversidade.

\section{Perspectivas de estudos em Ecologia de estradas}

Apesar de passagens de fauna estar sendo instaladas em todo o mundo, alguns autores têm levantado questionamentos sobre suas reais eficácias, bem como algumas curiosidades sobre o tema. Corlatti (2009) indaga sobre o número de passagens de fauna necessário para promover o fluxo gênico entre metapopulações numa determinada área com fragmentos isolados pelas rodovias. Além disso, também questiona sobre a efetividade das passagens de fauna para diversos grupos faunísticos, uma vez que cada tipo de passagem não atende a todos os grupos locais.

Outros pontos podem ser levantados em relação às passagens de fauna, como: no caso de poucos recursos para implantar medidas de mitigação em rodovias, qual tipo de passagem de fauna deve ser priorizado, no intuito de contemplar diferentes grupos faunísticos? Qual a eficiência das passagens de fauna em permitir o fluxo gênico e garantir a permanência das populações na paisagem, em longo prazo? Quais deveriam ser os tamanhos em altura e a 
extensão das cercas de condução? $O$ efeito da cerca condutora poderia ser negativo em algumas situações (Corlatti, 2009)?

Little et al. (2002) abordam algumas questões relacionadas aos predadores, que podem utilizar as passagens de fauna como armadilhas, e ainda fazem outros questionamentos, como: Os predadores marcam as passagens de fauna como território? As presas evitam passagens de fauna ou as utilizam em horários diferentes daqueles utilizados pelos predadores?

Sendo a Ecologia de Estradas uma nova disciplina, alguns métodos ainda não foram testados, como a eficiência de diferentes passagens de fauna para diferentes grupos faunísticos no tocante à sua estrutura (tamanho, comprimento, altura, material utilizado), desenho (formato das passagens de fauna) e a estrutura da paisagem do entorno (tipo de hábitat, matrizes, tamanho do fragmento florestal ou corpo d’agua mais próximos das passagens). Os trabalhos realizados, e principalmente aqueles que tratam sobre a eficiência das passagens de fauna, são focados geralmente no grupo dos mamíferos de médio e grande porte, os quais são os mais ameaçados em todo o mundo e que também apresentam maiores riscos aos usuários, causando acidentes mais graves (Beckmann et. al., 2010).

Em todo o mundo, os estudos relacionados à Ecologia de Estradas têm sido aplicados para mitigar os efeitos das rodovias nos ambientes naturais. Os países da Europa e da América do Norte se destacam nos estudos em Ecologia de Estradas por apresentarem maior número de estudos em longo prazo em rodovias sobre atropelamento de animais selvagens, aplicações das medidas de mitigação e monitoramento dessas medidas. No Brasil, a malha rodoviária, principalmente das regiões Norte, Nordeste e Centro- Oeste tem crescido por 
conta dos programas do PAC, mas o país ainda não apresenta um plano nacional para mitigação dos impactos da expansão da infraestrutura rodoviária. 


\section{Objetivos}

O presente estudo teve como objetivo geral monitorar por um ano o uso de mamíferos de médio e grande porte em dez passagens inferiores de fauna (PIFs) da Rodovia SP-225, a fim de verificar e comparar a efetividade de diferentes modelos de PIF, fornecendo subsídios aos órgãos competentes no sentido de diminuir a morte de fauna por atropelamentos e aumentar a conectividade funcional entre fragmentos de habitat nas paisagens cortadas por rodovias.

Dentre os objetivos específicos, temos:

- correlacionar o tipo estrutural das PIFs com as travessias por diferentes espécies de mamíferos de médio e grande porte;

- comparar a efetividade de dois métodos empregados para detecção de espécies de mamíferos de médio e grande porte nas PIFs: registro de pegadas em canteiros e imagens com câmeras de vídeo;

- verificar a importância da paisagem na zona de influência das PIFs, consideradas como 50 metros em seu entorno;

- sugerir ao órgão estadual licenciador de rodovias (CETESB - Companhia de Tecnologia e Saneamento Ambiental) algumas diretrizes para implantação de PIFs no estado de São Paulo. 


\section{Métodos}

2.1- Área de estudo

As passagens inferiores de fauna (PIFs) estudadas estão localizadas na SP-225

(Figura 8), Rodovia Engenheiro Paulo Nilo Romano, que liga as regiões Sudeste e Noroeste do Estado e possui um tráfego de mais de 140 mil veículos por mês (Centrovias, 2012).

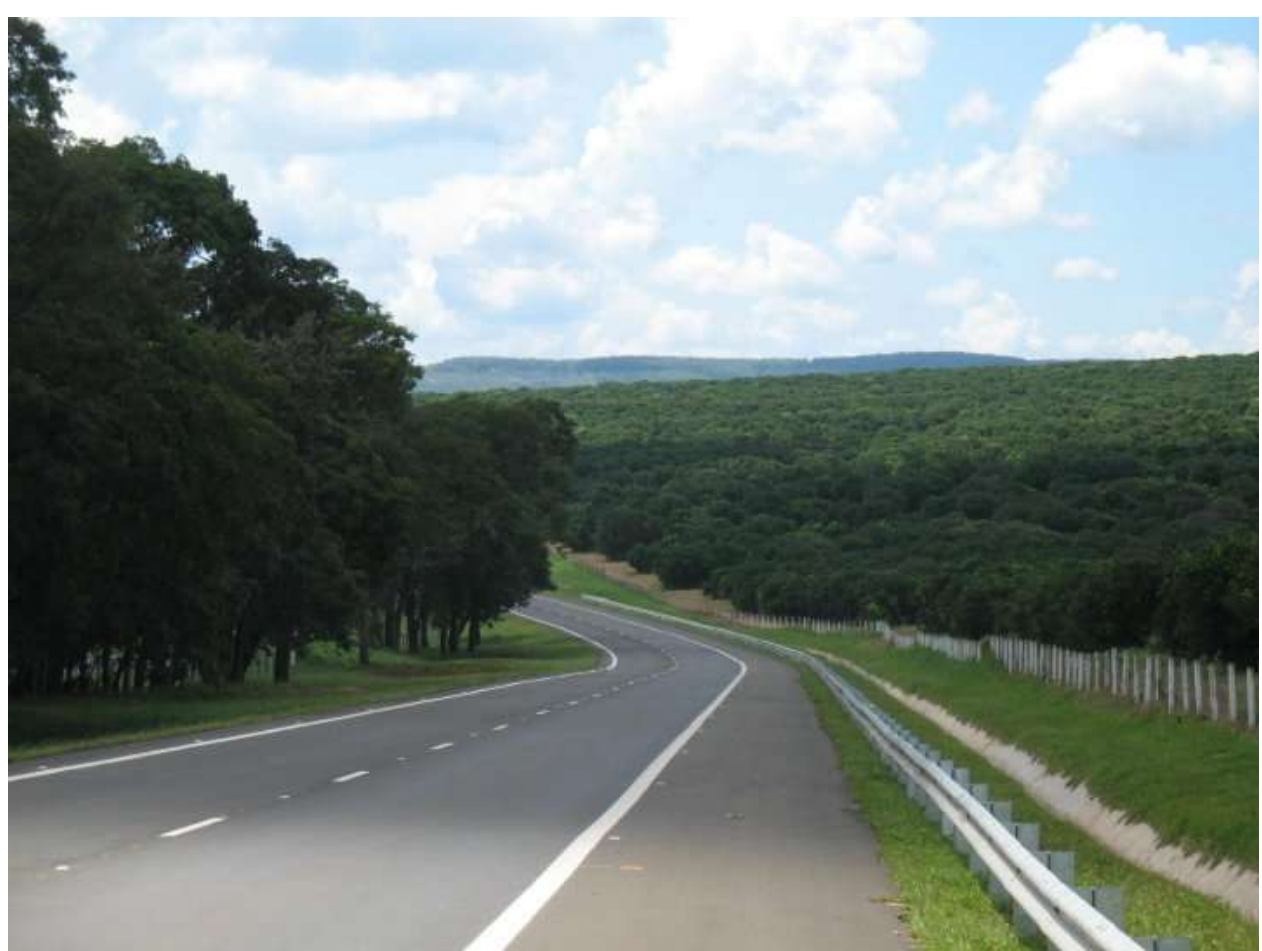

Figura 8 - Trecho da Rodovia Engenheiro Paulo Nilo Romano, SP-225, no município de Brotas (Foto: Fernanda D. Abra.).

As PIFs estudadas estão localizadas entre os quilômetros 102 e 153 da rodovia SP-225, totalizando 51 km de extensão e abrangendo os municípios de Dois Córregos, Brotas e Itirapina (Figura 9). A largura média da rodovia de estudo é de 30 metros, existindo algumas variações por conta de diferentes larguras do canteiro central em alguns pontos (Centrovias, 2012). Em fevereiro de 2008, foi entregue a obra de duplicação da SP-225, ligando as cidades de Jaú e Itirapina e totalizando $87 \mathrm{~km}$ da 
rodovia duplicados, com recapeamento na pista antiga, implantação de faixas de segurança e acostamentos e modernização de acessos, retornos e pontes. Durante o licenciamento da duplicação, também foram construídas novas galerias e passagens inferiores de fauna, exigidas pelos órgãos ambientais competentes (Escritório Regional do Instituto Brasileiro de meio Ambiente e dos Recursos Naturais Renováveis - IBAMA de Bauru/SP e Departamento Estadual de Proteção aos Recursos Naturais - DEPRN de Campinas/SP), a fim de diminuir os atropelamentos de animais silvestres ao longo dessa rodovia (IBAMA, 2012).

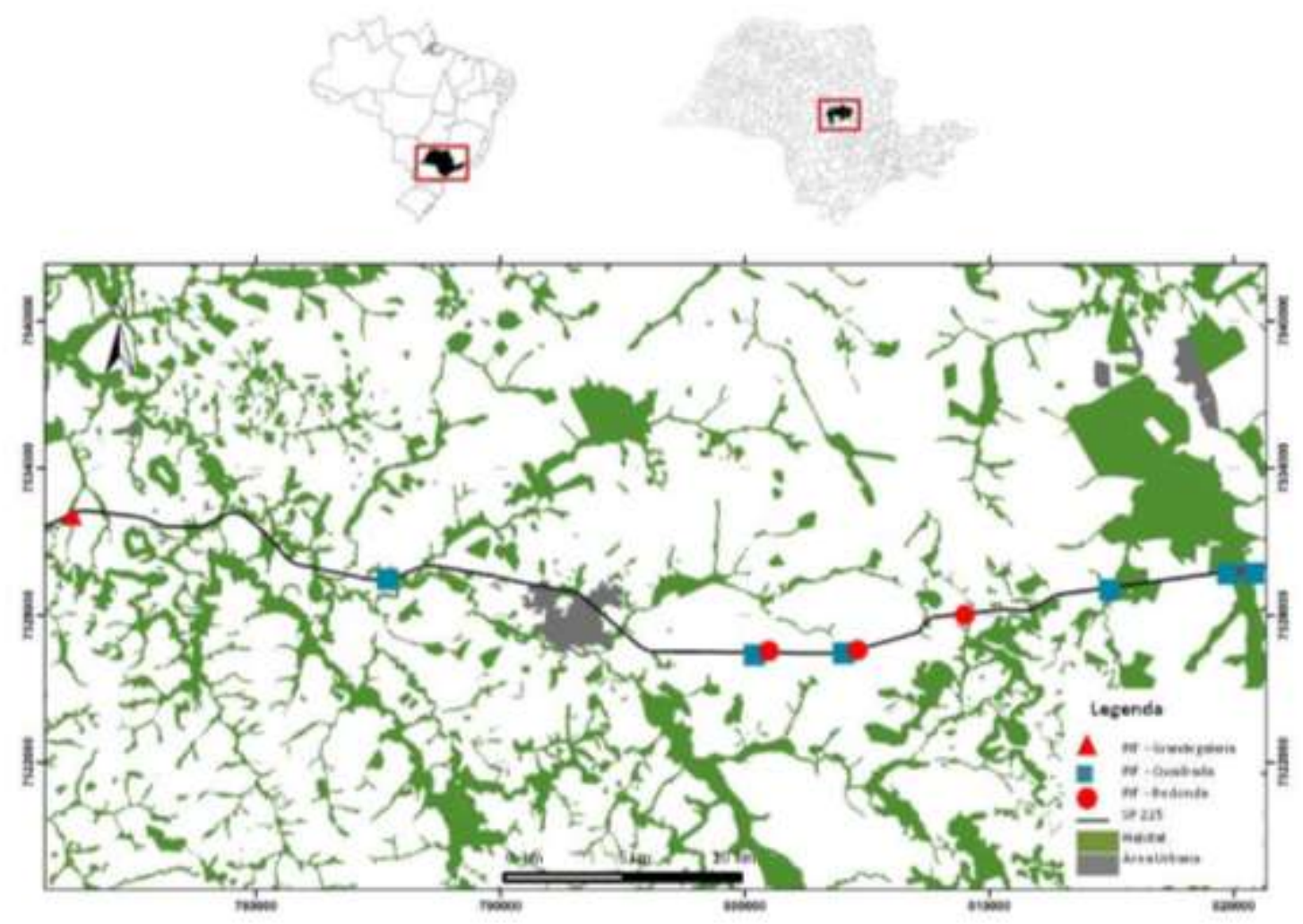

Figura 9 - Área de estudo e distribuição das PIFs ao longo da SP-225 (estado de São Paulo).

O maior trecho da área de estudo está localizado no município de Brotas que está localizado no centro do Estado de São Paulo (latitude $22^{\circ} 17^{\prime} 12$ Sul e longitude $48^{\circ}$ 
07`35 Oeste), apresenta altitude de 636,30 metros, uma área total de 1,062 $\mathrm{km}^{2}$ (ou 112.000 ha) e população de 21.580 habitantes (IBGE, 2012). O município conserva importantes fragmentos florestais de Mata Atlântica e Cerrado, faz parte das Estações Ecológicas de São Carlos e Itirapina.

O município de Brotas, juntamente com Dois Córregos e Itirapina apresentam, parte de seus territórios inseridos na Área de Proteção Ambiental (APA) de Corumbataí, que engloba mais 12 municípios e apresentou como motivação principal de sua criação atributos ambientais como as cuestas basálticas, os morros testemunhos, os recursos hídricos superficiais e o aqüífero Guarani, os remanescentes de vegetação nativa e o patrimônio arqueológico da região (Fundação Florestal, 2012; IBGE, 2012).

O município de Itirapina apresenta $564,183 \mathrm{~km}^{2}$ e possui 15.524 habitantes, a cidade está localizada a 770 metros de altitude em relação ao nível do mar, a fito fisionomia predominante é cerrado, com destaque à Estação Ecológica de Itirapina com 2300 ha, um dos maiores fragmentos de cerrado remanescentes no estado de São Paulo, campos sujos, campos cerrados e campos limpos predominam na paisagem da EEI, além de porções menores de cerrado sensu stricto, mata de galeria e brejos. O município possui diversos rios, represas e lagoas, dentre as principais se destacam: o rio Passa Cinco, o Ribeirão da Cachoeira, o Ribeirão do Feijão, o Rio Itaqueri e o Ribeirão do Lobo. Este último juntamente com o rio Itaqueri e alguns córregos menores são formadores da represa do Lobo (mais conhecida como Broa), que possui $8 \mathrm{~km} \mathrm{de}$ extensão (IBGE, 2012; Fundação Florestal, 2012; PMI, 2012).

Dois Córregos possui 632,973 km² e 24.761 habitantes, está localizada a $673 \mathrm{~m}$ de altitude, o único rio do município é o Rio Jaú, afluente do Rio Tietê, a vegetação é de zona de transição com floresta estacional semidecidual e cerradão (IBGE, 2012; Fundação Florestal, 2012). 
A área de estudo está submetida a um clima Cwa, segundo o sistema de Köppen (Setzer, 1966), ou seja, mesotérmico úmido de inverno seco. Esse clima é caracterizado por apresentar temperaturas mais elevadas no mês de janeiro e temperaturas mais amenas no mês de julho variando entre 18 e $20^{\circ} \mathrm{C}$ (Nimer, 1989). As chuvas concentram-se de outubro até março e o inverno se estende de abril a setembro. A área estudada localiza-se na divisão geomorfológica das Cuestas Basálticas (Ponçano et al., 1981).

\section{2 - Monitoramento das Passagens Inferiores de Fauna}

O monitoramento das PIFs ocorreu durante oito dias por mês, no período de um ano, totalizando um esforço amostral de 96 dias. Das 10 passagens amostradas, seis são do tipo celular de concreto, três do tipo redonda de tubo Armco e uma do tipo grande galeria (Figura 10). Além do tipo de estrutura, cada PIF teve suas dimensões anotadas, bem como a presença de água em seu interior e o fato de ter sido construída anterior ("nova") ou posteriormente ("antiga") ao licenciamento da duplicação da rodovia (Tabela 2). A fim de facilitar as análises, as PIFs foram identificadas pelo número do quilômetro onde estão localizadas, ex: PIF 153, localizada no km 153 da Rodovia SP225.

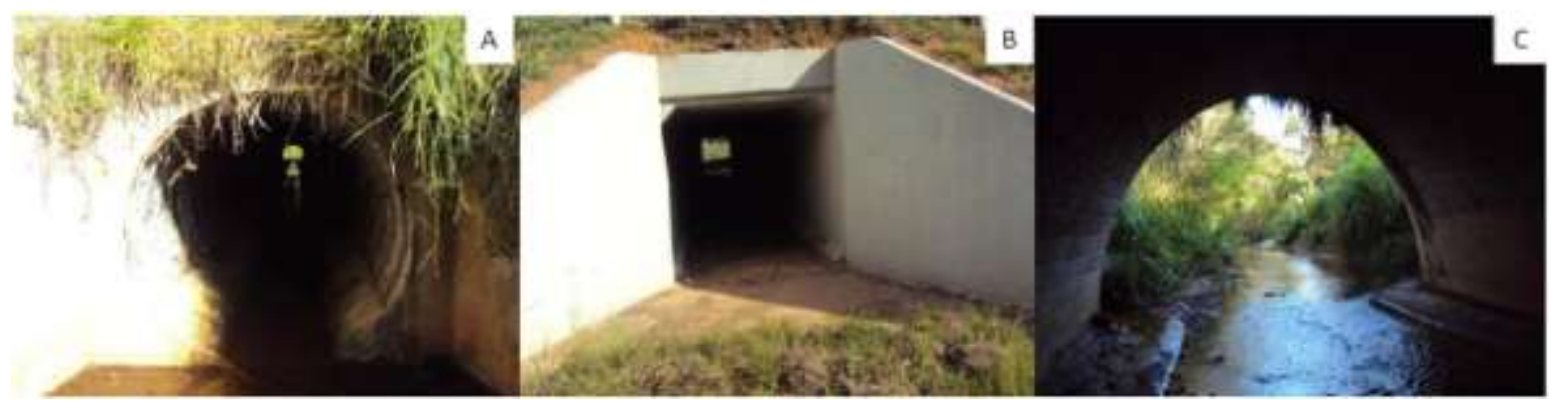

Figura 10 - Tipos de PIFs estudadas, localizadas na SP- 225: a) redonda, b) quadrada, c) grande galeria (Fotos: Fernanda D. Abra.)

Tabela 2 - Características estruturais das PIFs, classificação em novas e velhas e 


\begin{tabular}{|c|c|c|c|c|c|c|c|}
\hline PIF & $\begin{array}{l}\text { Dist. } \\
\text { Entre } \\
\text { PIFs } \\
(\mathrm{km})\end{array}$ & Tipo/Material & Nova/Antiga & $\begin{array}{l}\text { Altura } \\
\text { (m) }\end{array}$ & $\begin{array}{l}\text { Largura } \\
\quad(\mathrm{m})\end{array}$ & $\begin{array}{l}\text { Comprimento } \\
\text { (m) }\end{array}$ & $\begin{array}{c}\text { Presença/Ausência } \\
\text { de água na PIF }\end{array}$ \\
\hline 102 & $\begin{array}{c}102- \\
103 \\
(1)\end{array}$ & $\begin{array}{l}\text { Celular - } \\
\text { concreto }\end{array}$ & Nova & 2 & 2 & 32 & $\operatorname{sim}$ \\
\hline 103 & $\begin{array}{l}103- \\
107 \\
(4)\end{array}$ & $\begin{array}{l}\text { Celular - } \\
\text { concreto }\end{array}$ & Nova & 2 & 2 & 32 & $\operatorname{sim}$ \\
\hline 107 & $\begin{array}{c}107- \\
113 \\
(6)\end{array}$ & $\begin{array}{l}\text { Celular - } \\
\text { concreto }\end{array}$ & Nova & 2 & 2 & 33 & $\operatorname{sim}$ \\
\hline 113 & $\begin{array}{c}113- \\
118 \\
(5)\end{array}$ & $\begin{array}{l}\text { Redonda - } \\
\text { tubo Armco }\end{array}$ & Nova & 1,7 & 1,7 & 35 & não \\
\hline 118 & $\begin{array}{l}118- \\
119 \\
(1)\end{array}$ & $\begin{array}{l}\text { Redonda - } \\
\text { tubo Armco }\end{array}$ & Nova & 1,7 & 1,7 & 33 & $\operatorname{sim}$ \\
\hline 119 & $\begin{array}{l}119- \\
121 \\
(2)\end{array}$ & $\begin{array}{l}\text { Celular - } \\
\text { concreto }\end{array}$ & Antiga & 2,5 & 2,5 & 33 & $\operatorname{sim}$ \\
\hline 121 & $\begin{array}{c}121- \\
122 \\
(1)\end{array}$ & $\begin{array}{l}\text { Redonda - } \\
\text { tubo Armco }\end{array}$ & Nova & 1,5 & 1,5 & 63 & não \\
\hline 122 & $\begin{array}{l}122- \\
138 \\
(16)\end{array}$ & $\begin{array}{l}\text { Celular - } \\
\text { concreto }\end{array}$ & Antiga & 2,5 & 2,5 & 60 & não \\
\hline 138 & $\begin{array}{l}138- \\
153 \\
(15)\end{array}$ & $\begin{array}{l}\text { Celular - } \\
\text { concreto }\end{array}$ & Antiga & 2,5 & 2,0 & 34 & não \\
\hline 153 & - & $\begin{array}{c}\text { Open spam - } \\
\text { concreto }\end{array}$ & Antiga & 55 & 30 & 60 & $\operatorname{sim}$ \\
\hline
\end{tabular}

Para cada passagem, foi instalada uma câmera digital de vídeo com sensor infravermelho (da marca STEALTH CAM), em sua porção mediana (Figua 11). As câmeras eram instaladas no primeiro dia do monitoramento e retiradas somente no oitavo dia. Os 
vídeos eram armazenados em cartões de memória e depois descarregados no computador, para contabilizar as travessias e eventos (Anexo 1).

Foram também instaladas parcelas de pó de mármore, em ambas as aberturas das estruturas, numa profundidade de 3-10 mm, para o registro das pegadas dos animais (Figura 11). Em passagens úmidas, na impossibilidade de empregar as parcelas de pó de mármore, as pegadas foram contabilizadas quando havia registro em ambas as aberturas das estruturas, em bancos naturais de areia ou terreno argiloso. As pegadas foram verificadas a cada três dias, fotografadas e identificadas (Figura 12), com o auxílio de guias de campo e manuais específicos (Becker \& Dalponte, 1991) e pela experiência da pesquisadora.

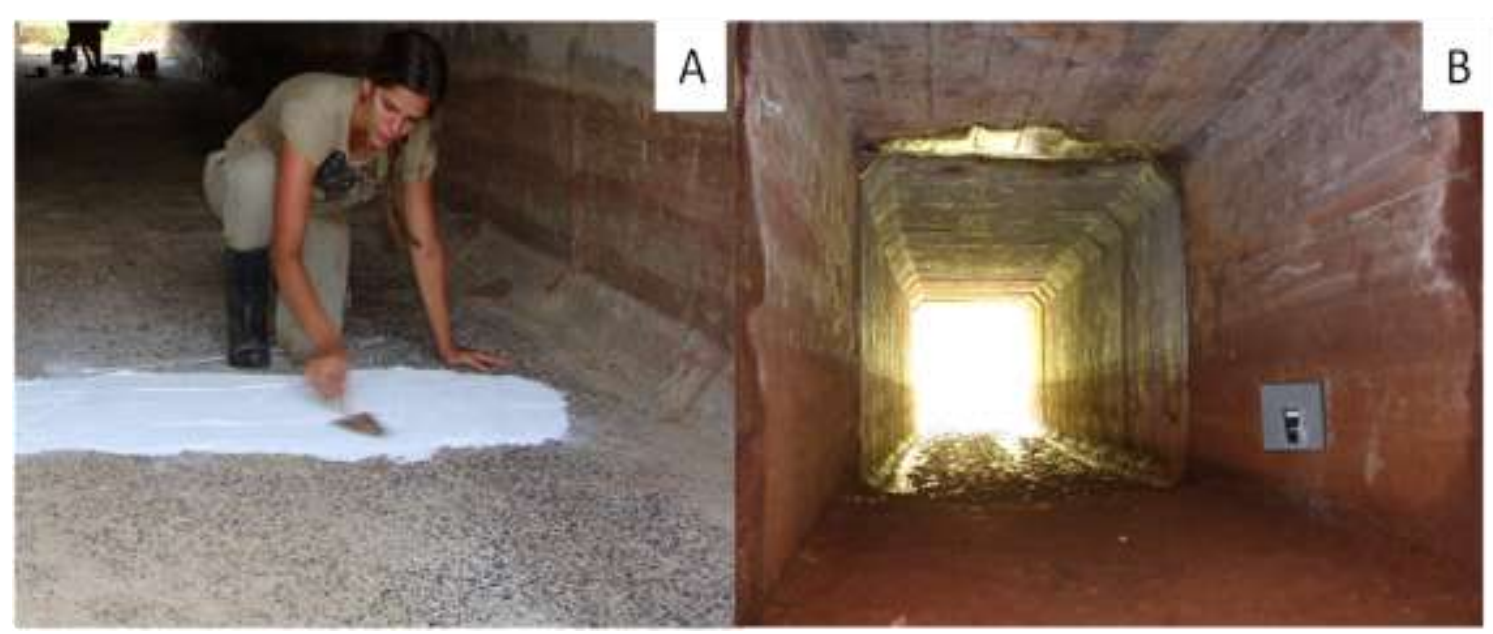

Figura 11 - Tipos de monitoramento efetuados nas PIFs estudadas (rodovia SP-225, SP): a) canteiro de pó de mármore, b) câmera de vídeo. (Fotos: Fernanda D. Abra.) 

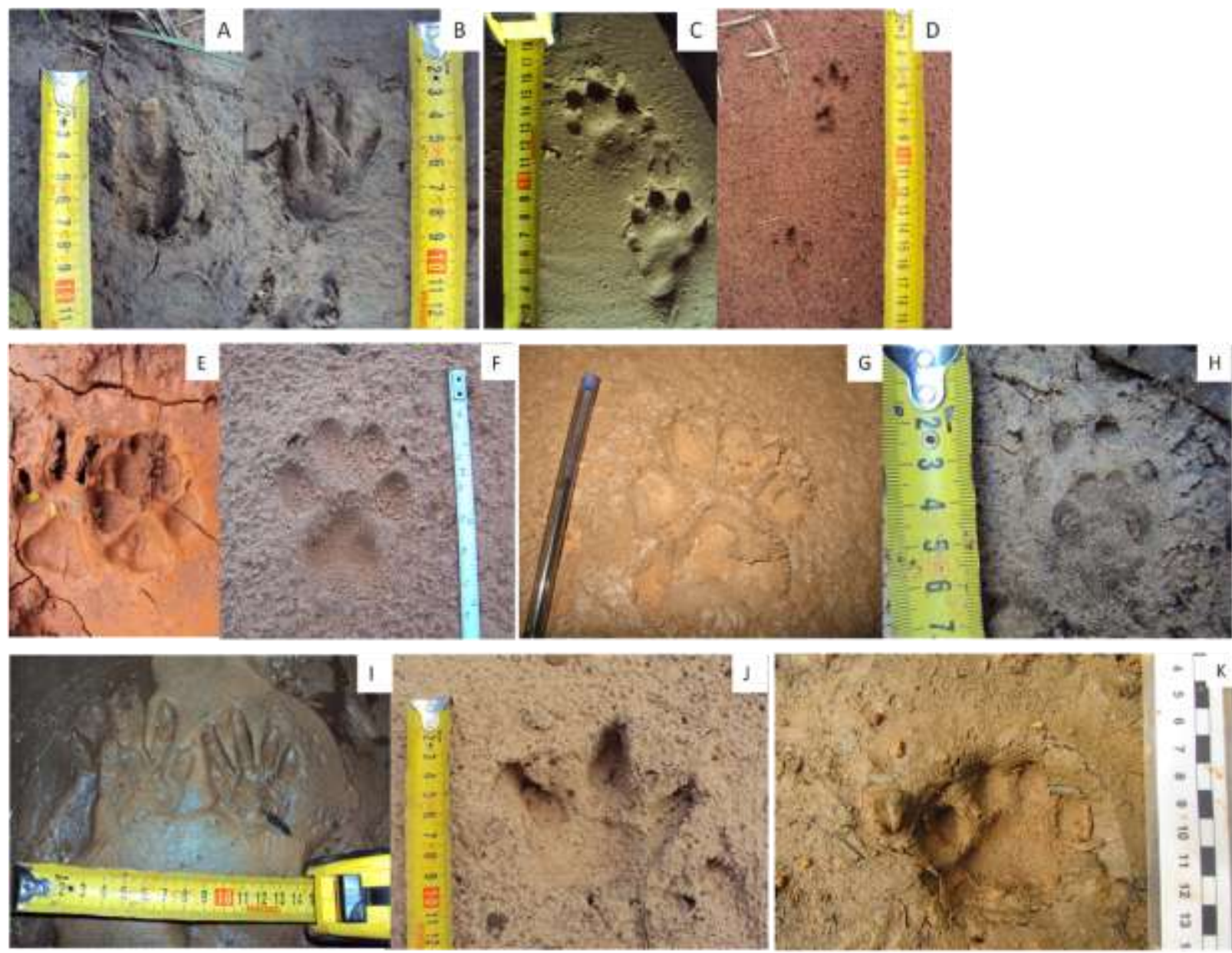

Figura 12 - Pegadas registradas em canteiros com pó de mármore ou em substrato natural, para detecção de travessias de mamíferos de médio e grande porte. A) veado catingueiro (Mazama gouazoubira), B) paca (Agouti paca), C) lontra (Lutra longicaudis), D) tatu galinha (Dasypus novemcinctus), E) lobo guará (Chrysocyon brachyurus), F) cachorro do mato (Cerdocyon thous), G) onça parda (Puma concolor), H) gato mourisco (Puma yagouaroundii), I) mão pelada (Procyon cancrivorus), J) capivara (Hydrochoerus hydrochaeris), K) jaguatirica (Leopardua pardalis).

Os registros de vídeo do uso de mamíferos de médio e grande porte em PIFs eram contabilizados de duas formas: eventos e travessias de indivíduos. Os eventos significam a travessia de um ou mais indivíduos juntos nas passagens. Por exemplo, a cada vez que a câmera era acionada, era contabilizado um evento, mas isso não significava que somente um indivíduo usava a passagem. Para registro de capivaras, por exemplo, as câmeras eram acionadas uma vez, contabilizando um evento, porém, grupos de até 17 indivíduos eram contados em cada vídeo. As travessias dizem respeito a cada animal (indivíduo) que atravessou a PIF. 
3.3 - Análise de dados

Para testar a significância das diferenças estruturais de cada PIF, da presença de água e a preferência de capivara (Hydrochoerus hydrochoeris) por passagens secas ou úmidas, foi usado o teste não paramétrico do Qui-quadrado (Zar 1999).

A fim de testar a preferência no uso de travessias de mamíferos de médio e grande porte quanto ao tipo estrutural das passagens - quadrada, redonda e grande galeria - foi utilizada uma análise de variância one-way (Zar 1999), onde o fator foi o tipo da PIF e a variável-resposta foi o número de indivíduos por espécie. Devido ao baixo número de cada tipo de PIF amostrado, o número de registros de cada espécie que utilizou PIF foi dividido pelo número de PIFs, a fim de eliminar o efeito do esforço (= número de PIFs). Cada espécie foi considerada como uma réplica, no intuito de se ter maior variabilidade do uso de PIFs por diferentes táxons. Também foi utilizada uma análise de variância two-way para testar a diferença de uso entre passagens antigas e novas (colocadas após a duplicação da rodovia). Os registros de travessias obtidos tanto por meio de vídeos quanto de pegadas foram comparados entre as passagens.

Todos os testes foram realizados com o Software R - versão 2.1.0.1.

\section{4 - Análises da paisagem}

O mapeamento de ocupação e uso das terras na área de estudo foi realizado por meio do Software ArcGis 9.2, com imagens do satélite CIBERS do tipo 2b CCD, bem como imagens retiradas do Google Earth ${ }^{\mathrm{TM}}$ tratadas manualmente, com resolução de 5 m e validação em campo. A legitimidade das interpretações foi verificada através do índice Kappa (Ferreira, 2010). 
A partir de cada PIF, foram criadas máscaras (buffers) de 50 a $300 \mathrm{~m}$ de diâmetro, a fim de investigar a paisagem no entorno do trecho considerado da rodovia SP-225 e, a partir disso, reconhecer padrões que influenciariam as espécies no uso de determinadas PIFs, em escala local.

As estruturas da paisagem consideradas dentro das máscaras foram: presença/ausência de corpos d’água, presença/ausência de habitat, presença de diferentes matrizes, como: i) pasto, ii) cultura de cana de açúcar, iii) citricultura, iv) silvicultura. Foram considerados como habitat os fragmentos de Cerrado e Mata Atlântica, uma vez que essa é a vegetação nativa da região. Quando essas estruturas não se encontravam presentes dentro das máscaras consideradas, foram medidas as distâncias mínimas das PIFs aos corpos d'água e fragmentos florestais fora das máscaras.

Para as espécies mais freqüentes nas travessias e algumas de interesse específico (ex. carnívoros canídeos como lobo guará - Chrysocyon brachyurus e cachorro do mato - Cerdocyon thous) foi realizado teste de correlação de Spearman a fim de verificar as espécies escolhidas relacionadas com o uso e cobertura da terra.

3.5 - Avaliação da existência de medidas mitigatórias aos atropelamentos no estado de São Paulo

A avaliação da existência de medidas mitigatórias aos atropelamentos de animais silvestres no estado de São Paulo, tais como passagens inferiores de fauna ou quaisquer outros tipos de medida mitigatória nas rodovias principais do estado paulista, foi realizada com base em consultas, via ofício ao DER (Departamento de Estrada e Rodagem do Estado de São Paulo) e à ARTESP (Agência Reguladora de Serviços Públicos Delegados de Transportes do Estado de São Paulo). 


\subsection{Monitoramento e avaliação das PIFs}

Durante o monitoramento, um total de 21 espécies, incluindo o grupo focal deste estudo - mamíferos de médio e grande porte - e outras espécies, utilizaram as PIFs somando 800 travessias (Tabela 3).

Tabela 3 - Número total de travessia por espécie de mamífero de médio e grande porte que utilizou as PIFs e, quando pertinente, seus respectivos graus de ameaça nas listas de espécies ameaçadas do estado de São Paulo (SMA, 2012), do Brasil (ICMBIO, 2012) e da IUCN - International Union for Conservation of Nature (IUCN, 2012). Na porção inferior da tabela encontram-se espécies não pertencentes ao grupo focal deste trabalho, representados por mamíferos de pequeno porte (roedores) ou exóticos (Felis catus), répteis (Tupinambis merianae), serpentes não identificadas, e aves não identificadas, detectados pelos dois métodos empregados no monitoramento.

\begin{tabular}{ccccc}
\hline Espécie & $\begin{array}{c}\text { Total de } \\
\text { travessias }\end{array}$ & \multicolumn{3}{c}{ Grau de ameaça } \\
Hydrochoerus & & estado de São Paulo & Brasil & IUCN \\
hydrochoeris & 435 & - & - & - \\
Mazama gouazoubira & 94 & - & - & - \\
Dasypus sp. & 52 & - & - & - \\
Didelphis albivenbtris & 37 & - & - & - \\
Chrysocyon brachyurus & 26 & $\mathrm{X}(\mathrm{vulnerável)}$ & $\mathrm{X}$ & $\mathrm{X}$ (pouco \\
Agouti paca & 22 & - & - & ameaçado) \\
Cerdocyon thous & 18 & - & - & $\mathrm{X}$ (pouco \\
Lutra longicaudis & 13 & - & - & preocupante) \\
Leopardus pardalis & 7 & $\mathrm{X}$ (vulnerável) & $\mathrm{X}$ & - \\
\end{tabular}




\begin{tabular}{ccccc} 
Procyon cancrivorus & 7 & - & - & - \\
Sus scrofa & 5 & - & - & $\mathrm{X}$ (Pouco \\
Tamandua tetradactyla & 3 & - & - & preocupante) \\
Nasua nasua & 2 & - & - & - \\
Puma yagouarundii & 2 & - & $\mathrm{X}$ & $\mathrm{X}$ (Pouco \\
Puma concolor & 1 & $\mathrm{X}$ (vulnerável) & - \\
Galictis cuja & 1 & - & & \\
Total & 725 & & & \\
\hline Tupinambis merianae & 25 & & \\
Felis catus & 25 & & \\
Serpente NI & 1 & & \\
Roedor NI & 18 & & \\
Ave NI & 6 & & \\
Total & 800 & & \\
\hline
\end{tabular}

Dentre os mamíferos de médio e grande porte, 16 espécies foram identificadas, contabilizando 725 travessias. As espécies que mais utilizaram as passagens foram capivara (Hydrochoerus hydrochoeris), com 435 travessias de indivíduos, seguida de veado catingueiro (Mazama gouazoubira), com 94 indivíduos, e tatu (Dasypus novemcinctus), com 52 indivíduos (Figura 13). 

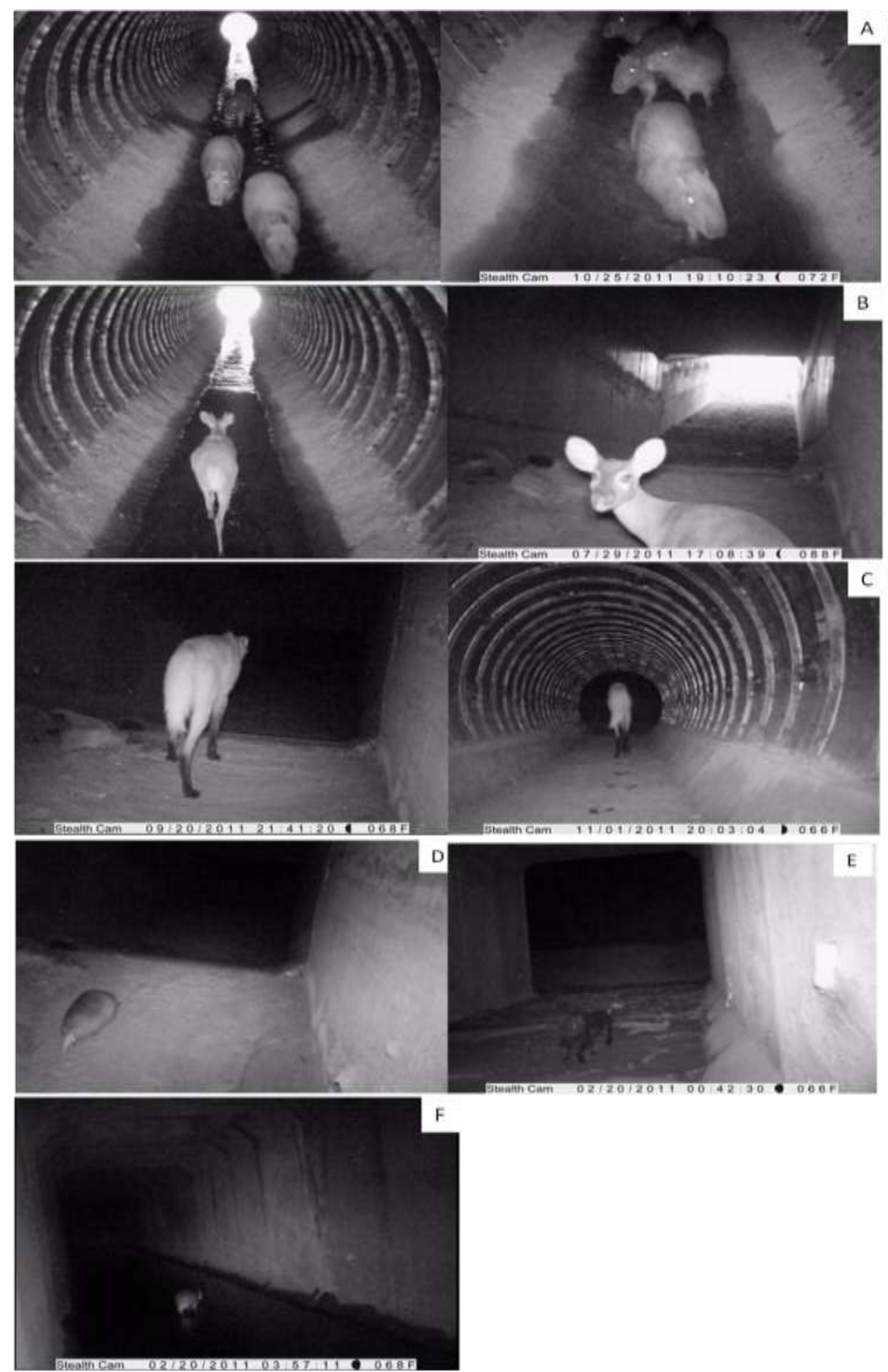

Figura 13 - Imagens congeladas das filmagens de travessias de algumas espécies: A) capivara (Hydrochoerus hydrochaeris), B) veado catingueiro (Mazama gouazoubira), C) lobo-guará (Chrysocyon brachyurus), D) tatu galinha (Dasypus novemcinctus), E) gato mourisco (Puma yagouarundii) e F) paca (Agouti paca). 
Dentre os diferentes métodos de registro de travessias aqui utilizados - registro através de filmagens com câmeras digitais e em canteiros de pegadas com pó de mármore - observa-se que o registro de pegadas foi mais eficiente para quase todas as espécies, com exceção de capivara (Hydrochoerus hydrochoeris) e veado catingueiro (Mazama gouazoubira). Em vários eventos, grupos de até 17 indivíduos de capivaras usaram as passagens e somente com o recurso de vídeo foi possível quantificar exatamente o número de animais, do mesmo modo fêmeas de veado catingueiro foram registradas com filhotes (Tabela 4).

Tabela 4 - Total de eventos para mamíferos de médio e grande porte pelos métodos de pegadas e vídeo.

\begin{tabular}{lll}
\hline Espécie & Pegada & Vídeo \\
\hline Hydrochoerus hydrochoeris & 26 & 67 \\
Mazama gouazoubira & 32 & 58 \\
Chrysocyon brachyurus & 18 & 8 \\
Dasypus novemcinctus & 43 & 9 \\
Didelphis albiventris & 37 & 0 \\
Agouti paca & 7 & 15 \\
Leopardus pardalis & 6 & 1 \\
Cerdocyon thous & 17 & 1 \\
Lutra longicaudis & 13 & 0 \\
Puma yagourundi & 1 & 1 \\
Nasua nasua & 2 & 0 \\
Procyon cancrivorus & 7 & 0 \\
Puma concolor & 1 & 0 \\
Galictis cuja & 1 & 0 \\
Tamandua tetradactyla & 3 & 0 \\
Sus scrofa & 5 & 0 \\
Total & 219 & 160 \\
\hline
\end{tabular}


Dentre as PIFs que registraram mais eventos (Tabela 5) e, portanto, foram mais utilizadas, foram a PIF-118, que totalizou 107 eventos, sendo 58 desses eventos somente de capivaras, a PIF-153 registrou 53 eventos de 11 diferentes espécies, sendo a primeira PIF em número de riqueza de espécies, seguida da PIF-102, com 44 eventos de quatro espécies diferentes apresentando uma relevante importância por ser a PIF mais próxima da Estação Ecológica de Itirapina.

\section{Tabela 5 - Número de eventos para cada PIF com os métodos de pegada e vídeo.}

\begin{tabular}{llll}
\hline PIF & Pegada & Vídeo & Total de eventos \\
\hline 102 & 17 & 27 & 44 \\
103 & 16 & 13 & 29 \\
107 & 29 & 4 & 33 \\
113 & 9 & 3 & 12 \\
118 & 11 & 96 & 107 \\
119 & 16 & 3 & 19 \\
121 & 10 & 1 & 11 \\
122 & 30 & 4 & 34 \\
138 & 28 & 9 & 37 \\
153 & 53 & 0 & 53 \\
Total & 219 & 160 & 379 \\
\hline
\end{tabular}

De acordo com a análise de variância para testar se a quantidade de travessias nas diferentes forma de PIFs diferiram, não houve diferença (ANOVA, $F=1.43 ; p=0$, 2553) (Figura 14). A única PIF que difere em tamanho e proporções é a PIF-153 do tipo grande galeria, que contemplou a travessia de várias espécies. 


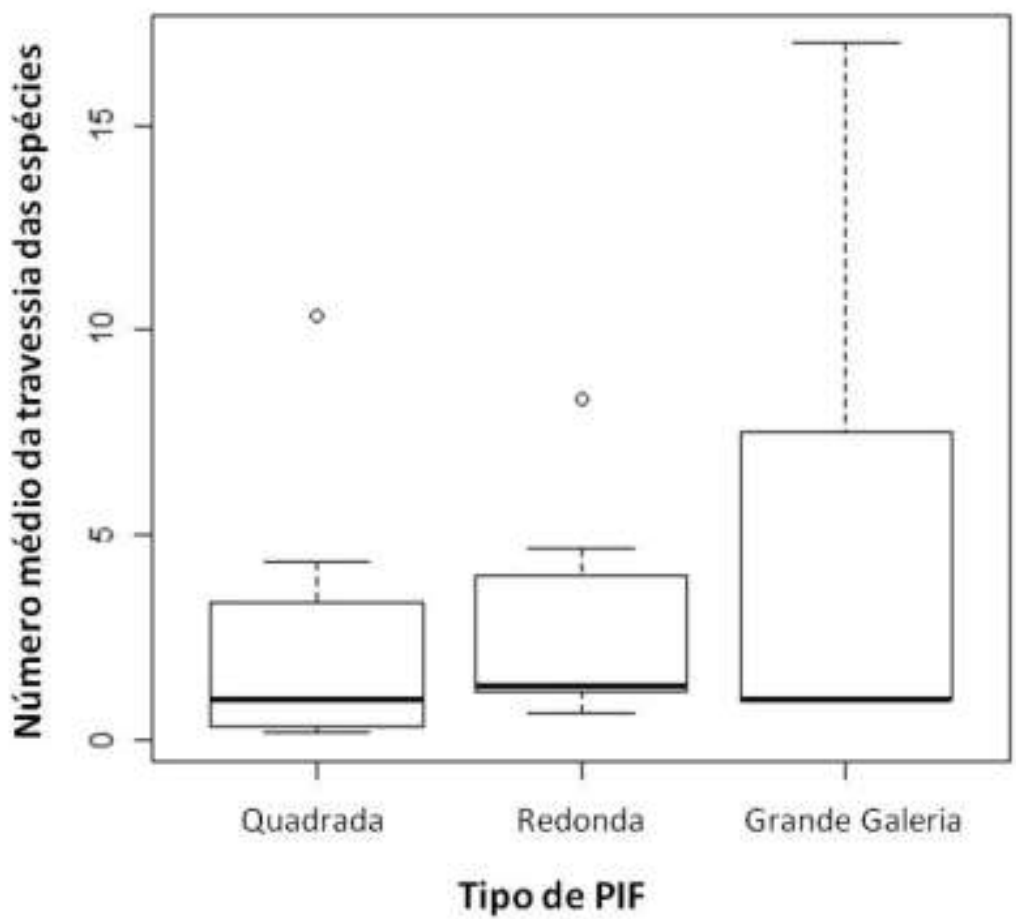

Figura 14 - Passagens quadradas, redondas e grande galeria não apresentaram diferença quanto o número médio de travessias por espécie (ANOVA, $\mathrm{F}=1.43, \mathrm{n}=33, \mathrm{p}=0,255$ ).

A avaliação da preferência por passagens secas ou úmidas mostrou que a presença de água foi um fator altamente significativo para promover a travessia da fauna de modo geral $\left(X^{2}=236,5 ; P<<0,001\right)$ e, especialmente, da capivara $\left(X^{2}=344,3\right.$; $\mathrm{P}<<0,001)$.

A diferença em travessias no uso de passagens novas (que foram implantadas depois da duplicação da rodovia) e passagens antigas não se mostrou significativa $($ ANOVA, $\mathrm{F}=0,4692 ; \mathrm{P}=0,0,5127)$ (Figura 15). 


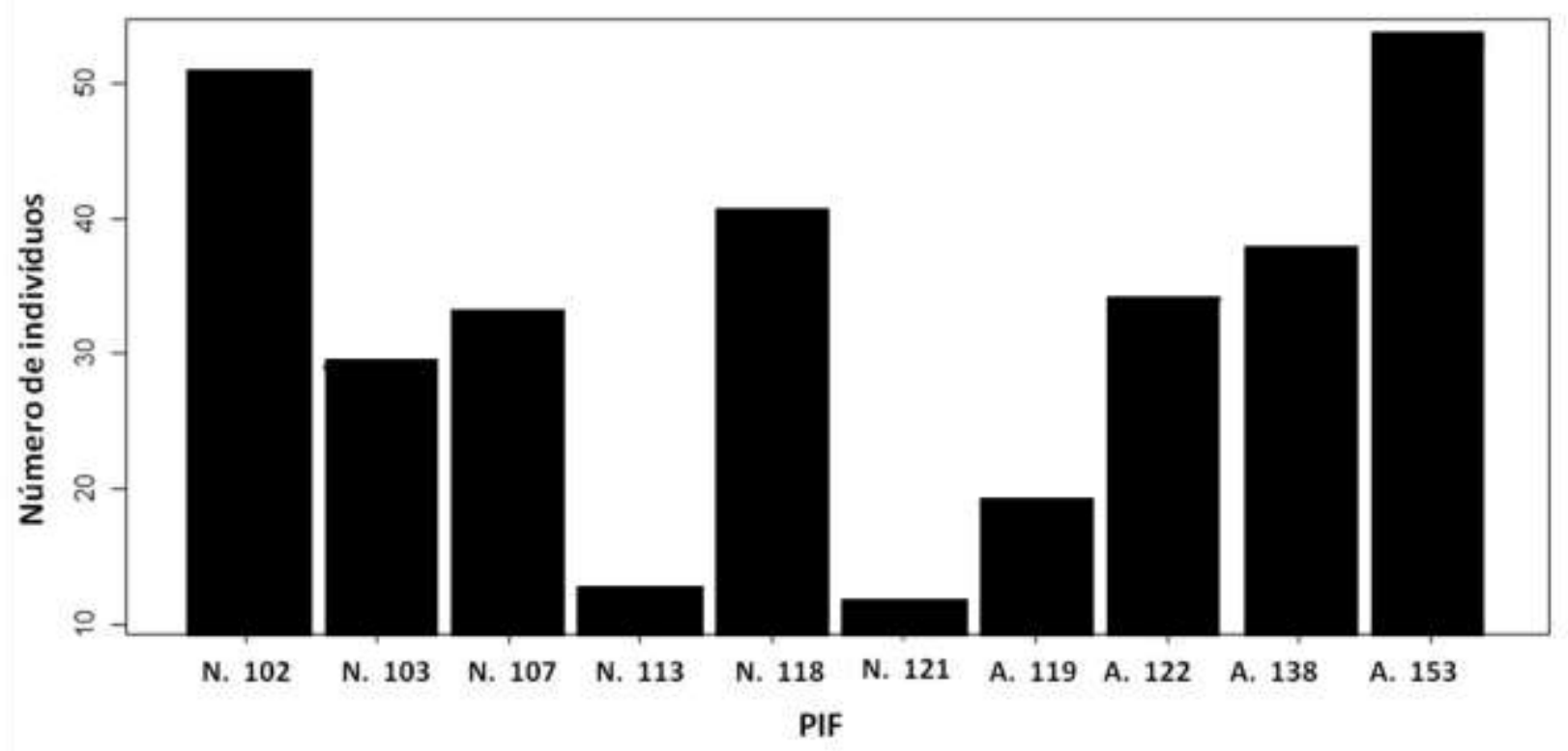

Figura 15 - Comparação entre as médias das travessias de número de indivíduos entre passagens novas $(\mathrm{N})$ e antigas $(\mathrm{A})$.

\subsection{Análise da Paisagem}

A legitimidade das interpretações da classificação do uso e ocupação do solo foi verificada através do índice Kappa que apresentou um valor de 92,55 (Ferreira, 2010).

Uma vez que os diversos tamanhos de máscaras testadas $(50,100,200$ e 300 metros) não mostraram diferença quanto à presença das estruturas da paisagem estudadas, foi adotada somente a máscara de 50 metros, que é uma escala adequada para análises locais, implicando, portanto, na percepção visual dos mamíferos de médio e grande porte das PIFs e não da paisagem para o deslocamento das espécies.

Os tipos de cobertura e uso das terras nas máscaras de 50 metros ao redor de cada PIF, bem como a presença de água e tipo de habitat mostram que as matrizes de citricultura e silvicultura eram as que mais estavam presentes no entorno das passagens (Figura 16). Em quase todas as PIF em cujas máscaras havia água, também havia 
presença de água no interior dessas PIFs, caracterizando, portanto, seis PIFs com água e quatro secas (Tabela 6) As únicas máscaras que apresentaram habitat foram as PIFs 102, 103 e 107 com predomínio de fitofisionomias de cerrado. 

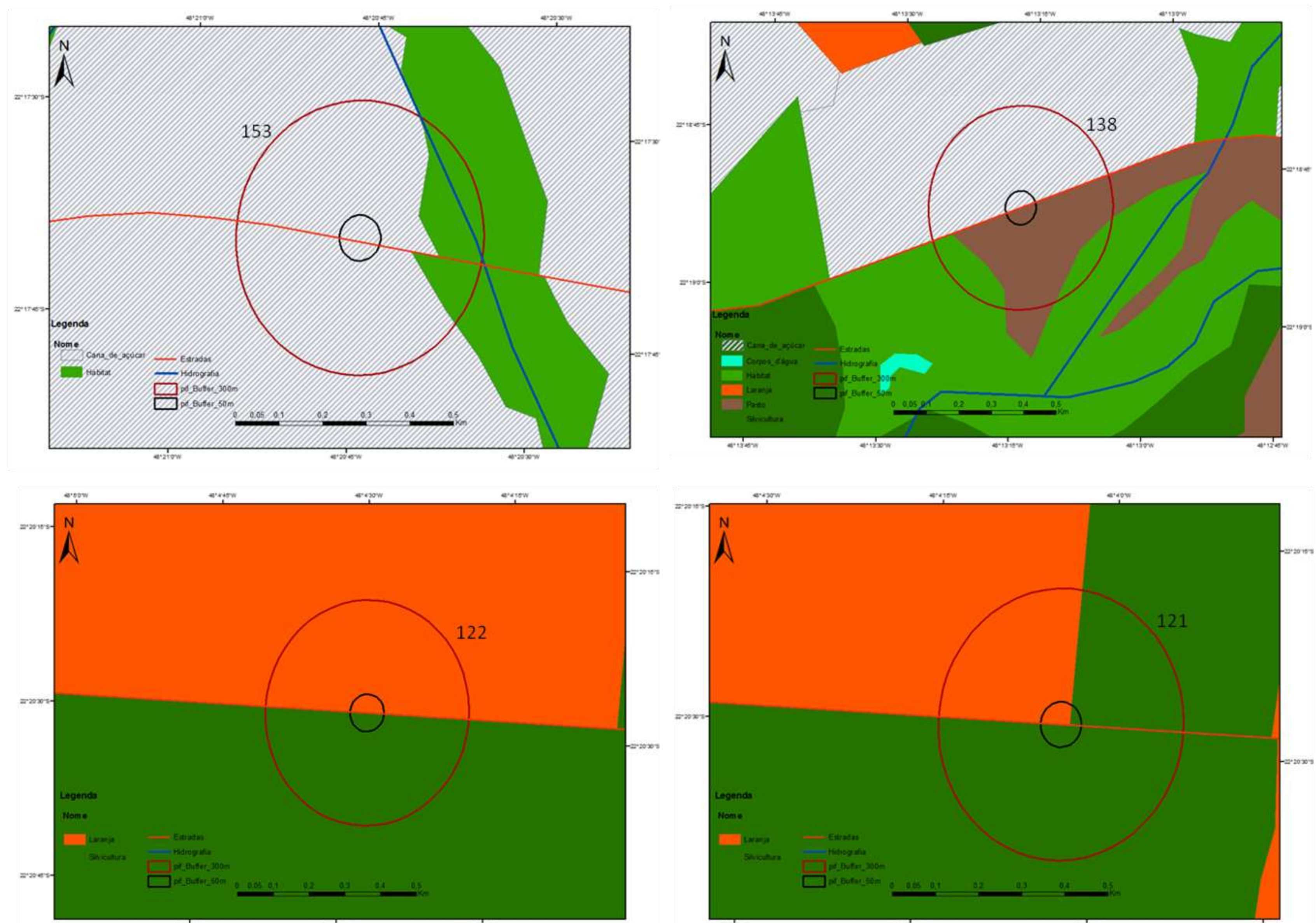

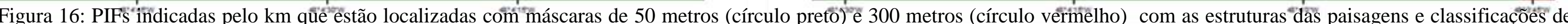
uso do solo. Legenda: laranja = citricultura, verde escuro = silvicultura, verde claro = hábitat, marrom = pasto, azul claro = corpo d'agua, hachurado $=$ cana de açúcar, linha vermelha = SP-225, linha azul = córrego. 

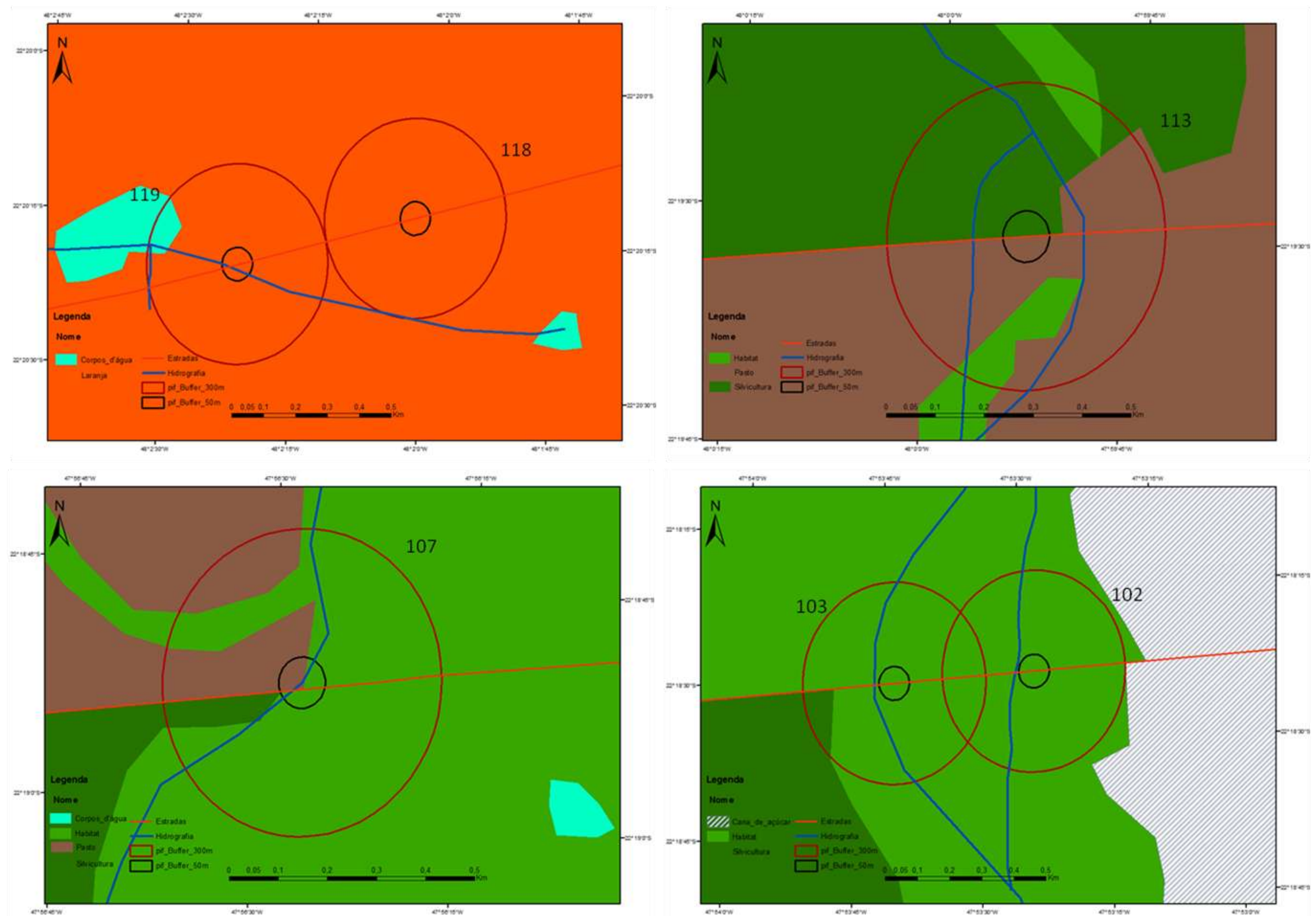

Figura 16: PIFs indicadas pelo km que estão localizadas com máscaras de 50 metros (círculo preto) e 300 metros (círculo vermelho) com as estruturas das paisagens e classificações de uso do solo. Legenda: laranja = citricultura, verde escuro = silvicultura, verde claro = hábitat, marrom = pasto, azul claro = corpo d'agua, hachurado = cana de açúcar, linha vermelha = SP-225, linha azul = córrego. 
Tabela 6 - Estrutura da paisagem e matrizes de cada máscara.

\begin{tabular}{|c|c|c|c|}
\hline PIF & $\underset{\text { Matriz_máscara }}{ } 50$ & $\begin{array}{c}\text { Presença de água_máscara } \\
50 \mathrm{~m}\end{array}$ & $\begin{array}{c}\text { Presença de habitat_máscara } \\
50 \mathrm{~m}\end{array}$ \\
\hline 102 & - & $\operatorname{sim}$ & $\operatorname{sim}$ \\
\hline 103 & - & $\operatorname{sim}$ & $\operatorname{sim}$ \\
\hline 107 & pasto - silvicultura & $\operatorname{sim}$ & $\operatorname{sim}$ \\
\hline 113 & pasto - silvicultura & $\operatorname{sim}$ & $\operatorname{sim}$ \\
\hline 118 & Laranja & $\operatorname{sim}$ & não \\
\hline 119 & Laranja & não & não \\
\hline 121 & $\begin{array}{c}\text { laranja - } \\
\text { silvicultura }\end{array}$ & não & não \\
\hline 122 & $\begin{array}{l}\text { laranja - } \\
\text { silvicultura }\end{array}$ & não & não \\
\hline 138 & Silvicultura & não & $\operatorname{sim}$ \\
\hline 153 & Cana & $\operatorname{sim}$ & $\operatorname{sim}$ \\
\hline
\end{tabular}

Os testes de Spearman entre a ocorrência das espécies nas diferentes matrizes das áreas das máscaras de 50 metros, a única espécie que respondeu à paisagem foi o gambá (Didelphis albiventris) $(\mathrm{p}=0,042)$, com maior frequiência de travessia em PIFs em áreas de pastagem e cultivo de cana de açúcar. Todas as outras espécies não demonstraram relação com o uso e cobertura do solo nas máscaras estudadas.

O Teste de correlação de Spearman apontou correlação negativa significativa entre a ocorrência de cachorro do mato (Cerdocyon thous) e paisagens com água, de igual modo para tatu (Dasypus novemcinctus), que nesse estudo foi relacionado às áreas mais abertas da paisagem estudada (Tabela 7). De outra maneira, paca, gambá e veado foram relacionados com paisagens em que o habitat estava presente dentro das máscaras estudadas. Apesar do lobo guará (Chrysocyon brachyurus) também preferir áreas 
abertas como o cachorro do mato, nesse estudo as análises não apresentaram uma relação significativa.

\begin{tabular}{|c|c|c|c|c|}
\hline \multicolumn{5}{|c|}{$\begin{array}{l}\text { Tabela } 7 \text { - Coeficientes de correlação de Spearman referentes à ocorrência das } \\
\text { espécies e suas respectivas relações com o uso e cobertura da terra na paisagem } \\
\text { existente em máscaras de } 50 \text { metros. (* = correlações significativas a } 0,05) \text {. }\end{array}$} \\
\hline Ocorrência & $\begin{array}{l}\text { Distância } \\
\text { Mínima a corpos } \\
\text { d’água }\end{array}$ & $\begin{array}{l}\text { Distância Mínima a } \\
\text { fragmentos florestais }\end{array}$ & $\begin{array}{l}\text { Presença de corpo d'água } \\
\text { dentro da máscara ( } 50 \mathrm{~m})\end{array}$ & $\begin{array}{l}\text { Presença de hábitat } \\
\text { dentro da máscara }(50 \\
\mathrm{m})\end{array}$ \\
\hline $\begin{array}{c}\text { Didelphis } \\
\text { albiventris* }\end{array}$ & $-0,22$ & $-0,26$ & 0,24 & 0,38 \\
\hline Hydrochoeru & & & & \\
\hline s & $-0,31$ & 0,35 & 0,26 & $-0,42$ \\
\hline hydrochaeris & & & & \\
\hline $\begin{array}{c}\text { Mazama } \\
\text { gouazoubira }\end{array}$ & $-0,39$ & $-0,46$ & 0,36 & 0,37 \\
\hline Agouti paca & $-0,44$ & $-0,51$ & 0,42 & 0,40 \\
\hline $\begin{array}{c}\text { Dasypus } \\
\text { novemcinctus }\end{array}$ & 0,69 & 0,47 & $-0,62^{*}$ & $-0,44$ \\
\hline $\begin{array}{l}\text { Chrysocyon } \\
\text { brachyurus }\end{array}$ & 0,35 & $-0,21$ & $-0,39$ & 0,13 \\
\hline $\begin{array}{l}\text { Cerdocyon } \\
\text { thous }\end{array}$ & 0,83 & 0,42 & $-0,72 *$ & $-0,50$ \\
\hline
\end{tabular}

\subsection{Avaliação da existência de medidas de mitigação no estado de São Paulo}

Em resposta ao questionamento enviado ao DER e à ARTESP sobre a existência de passagens de fauna ou outros tipos de medidas de mitigação para atropelamento de animais silvestres, o DER respondeu sobre a não existência dessas estruturas em nenhum dos $16.000 \mathrm{~km}$, de rodovias pavimentadas, entre eixos, acessos e dispositivos, espalhados por todo o Estado. Ainda, na página do Órgão (http://www.der.sp.gov.br) não há indício de qualquer iniciativa na administração das suas rodovias sobre procedimentos e diretrizes para a diminuição de atropelamentos de animais silvestres 
para a conservação da biodiversidade ou para a própria segurança do usuário. A ARTESP, no entanto, apresentou uma relação de rodovias sob concessão que já apresentam medidas de mitigação como as PIFs. No estado de São Paulo, existem, portanto 71 passagens de fauna implantadas e dez a serem implantadas em quatorze rodovias diferentes, sob concessão de dez concessionárias paulistas (Tabela 7).

\section{Tabela 7- Número e localização de passagens de fauna subterrâneas em rodovias paulistas sob concessão (ARTESP, 2011).}

\begin{tabular}{|c|c|c|c|c|c|}
\hline Concessionária & $\begin{array}{c}\text { Extensão da } \\
\text { malha } \\
\text { rodoviária } \\
(\mathrm{km}) \\
\end{array}$ & $\begin{array}{l}\text { Rodovia (s) } \\
\text { com Passagem } \\
\text { Inferior de } \\
\text { fauna } \\
\end{array}$ & $\begin{array}{c}\text { Passagens } \\
\text { Inferior de } \\
\text { Fauna } \\
\text { implantadas } \\
\end{array}$ & $\begin{array}{c}\text { Passagens } \\
\text { Inferior de Fauna } \\
\text { a serem } \\
\text { implantadas } \\
\end{array}$ & Tota \\
\hline Autovias & 317 & $\begin{array}{c}\text { SP-255; SP- } \\
334\end{array}$ & $4 ; 8$ & - & 12 \\
\hline Centrovias & 219 & SP-225 & 18 & - & 18 \\
\hline $\begin{array}{l}\text { Rota das } \\
\text { Bandeiras }\end{array}$ & 300 & SP-063 & 1 & 2 & 3 \\
\hline SP Mar & 60 & SP-021 & 16 & - & 16 \\
\hline SP Vias & 516 & $\begin{array}{l}\text { SP-127; SP- } \\
\text { 255; SP- 258; } \\
\text { SP- 280; SP- } \\
270\end{array}$ & $11 ; 1 ; 1 ; 1 ; 2$ & - & 16 \\
\hline $\begin{array}{c}\text { Triângulo do } \\
\text { Sol }\end{array}$ & 443 & SP-333 & 2 & - & 2 \\
\hline Via Norte & 236,6 & SP-332 & 5 & - & 5 \\
\hline Via Oeste & 162 & SP-270 & 1 & - & 1 \\
\hline Via Rondon & 420 & SP-300 & - & 8 & 8 \\
\hline Autoban & 316,75 & - & - & - & - \\
\hline Colinas & 300 & - & - & - & - \\
\hline Ecovias & 177 & - & - & - & - \\
\hline Intervias & 375,7 & - & - & - & - \\
\hline Renovias & 345,6 & - & - & - & - \\
\hline Tebe & 156 & - & - & - & - \\
\hline Cart & 389 & - & - & - & - \\
\hline
\end{tabular}




\begin{tabular}{cccccc}
\hline Eco Pista & 134,9 & - & - & - & - \\
Rodo Anel & 32 & - & - & - & - \\
$(\mathrm{CCR})$ & & - & - & - \\
$\begin{array}{c}\text { Rodovias do } \\
\text { Tietê }\end{array}$ & 420 & - & - & 10 & 81 \\
TOTAL & $5.320,55$ & - & 71 & 10 \\
\hline
\end{tabular}




\section{Discussão}

Comparação dos métodos de registro utilizados

Um grande número de registros foi realizado no período deste estudo, tanto pelas câmeras de vídeo como pelos canteiros de pegadas. As câmeras de vídeo possuem um atraso para iniciar a filmagem a partir da detecção do movimento do animal na frente da câmera, portanto, inúmeras vezes as câmeras eram acionadas para iniciar as filmagens, mas as imagens eram vazias ou somente apresentavam parte dos calcanhares ou pontas dos rabos dos indivíduos saindo de cena, impossibilitando a identificação da espécie e a contabilização da travessia ou evento. As câmeras podem ser um recurso vantajoso para as espécies de maior porte, onde a detecção do movimento seja mais rápida por conta das massas corpóreas serem maiores, como nos casos do sucesso de registro de vídeo da própria capivara, dos veados e das pacas, como ocorreu neste monitoramento.

Os canteiros de pegadas são vantajosos por serem mais baratos. Por exemplo, o pó de mármore é excedente de produção de marmorarias e uma quantidade muito pequena, inferior a $1,5 \mathrm{~kg}$, é necessária para instalar um canteiro de pegada de $2 \mathrm{~m} \mathrm{x}$ 0,70 m. A qualidade da impressão das pegadas em pó de mármore é muito superior às pegadas detectadas por canteiros de areia, por conta do tamanho da granulatura do mármore, sendo que quanto mais fino, maior a chance de impressão de pegadas de qualidade até mesmo para pequenos mamíferos. A desvantagem desse método é não poder ser empregado em PIFs úmidas e também por não possibilitar a contagem de indivíduos que se deslocam em grupos e bandos, como no caso da capivara. Se nesse estudo fosse empregado somente método de pegada, não seria possível ter quantificado 
os exatos 435 indivíduos que usaram as PIFs, registradas por meio de vídeo, e esse número de travessias é responsável por $60 \%$ das travessias de mamíferos de médio e grande porte monitoradas nesse trabalho. É recomendável que sejam usados os dois métodos para monitoramento de passagens de fauna.

\section{Comparação entre espécies registradas}

O monitoramento realizado no presente estudo mostrou um maior uso das PIFs por espécies generalistas do que por espécies sensíveis, o que pode ser decorrência da própria área de estudo ser uma região antropizada. A área de estudo compõe uma paisagem fragmentada, onde existem alguns tipos de matrizes como citricultura, silvicultura, cana de açúcar e pastagem, que selecionem um maior deslocamento dessas espécies próximas à rodovia. É provável que espécies mais sensíveis evitem as rodovias e até mesmo locais próximos às rodovias, como detectado no estudo de Ascensão \& Mira (2006) em Portugal. Essa hipótese explicaria a ausência de registro de algumas espécies que existem na região (Delgado, 2004), como o tapeti (Sylvilagus brasiliensis), o ouriço cacheiro (Coendou prehensilis), o gato do mato pequeno (Leopardus tigrinus), a irara (Eira barbara) e a raposinha do campo (Pseudalopex vetulus), ou o baixo registro de outras espécies como o furão (Galictis cuja), jaguatirica (Leopardus pardalis), gato mourisco (Puma yagouarundii) e onça parda (Puma concolor) que pode ser explicado por densidades populacionais naturalmente baixas ou causadas pelos impactos de atropelamento, caça e demais consequências resultantes das fragmentação dos ambientes naturais.

A alta frequência de espécies nas PIFs, como o tatu galinha (Dasypus novemcinctus), o gambá (Didelphis albiventris) e o veado catingueiro (Mazama 
gouazoubira), se dá por serem menos sensíveis, com hábitos generalistas e possivelmente com números populacionais altos.

Dentre as espécies que mais utilizaram as passagens de fauna, a capivara (Hydrochoerus hydrochoeris) foi, sem dúvida, a mais frequente. Esta é uma espécie generalista e altamente adaptada às constantes mudanças de uso e cobertura dos solos. A PIF-118, de maior uso dessa espécie, está inserida numa matriz de citricultura e próxima a corpo d' água, o que permite a permanência de um grupo de capivaras habitando esse local.

Embora essa PIF tenha também contemplado a travessia de outras espécies, o grande número de travessias efetuadas por capivaras (407 travessias) a coloca numa importante situação relacionada à segurança do usuário, comparada às outras PIFs analisadas. Praticamente todos os dias durante o monitoramento, grupos de até 17 indivíduos ou parte desse grupo se deslocava pela PIF 118 e, a presença dessa passagem, em especial, diminuiu o risco do usuário em se envolver num acidente com a espécie. A capivara é uma espécie alvo para se trabalhar com implantação de medidas de mitigação com o objetivo de resguardar a segurança do usuário em rodovias, pois se trata de uma espécie generalista, presente em todo o estado de São Paulo em populações numerosas, adapta-se facilmente algumas culturas agrícolas e corpos d' água próximos às rodovias e, pelo seu tamanho, peso corporal - os adultos podem chegar a até $90 \mathrm{~kg}$ e o hábito de deslocamento em bandos, é uma real ameaça aos usuários, podendo resultar desde acidentes não fatais, porém com altos custos financeiros nos reparos do veículo, a acidentes fatais ao usuário.

De acordo com o banco de dados de três rodovias diferentes do estado de São Paulo, a SP-225 (Centrovias), a SP-330 (Autovias) e a SP-334 (Autovias), durante os anos de 2008, 2009 e 2010, o atropelamento de capivaras representou em média 40\% do 
total de atropelamento de espécies de mamíferos de médio e grande porte (ARTESP, 2011). Na rodovia SP-225, o atropelamento das capivaras em 2008 foi de $62,5 \%$ do total de espécies de mamíferos de médio e grande porte, e após a duplicação entregue em fevereiro de 2008 com as novas passagens, o atropelamento caiu para 33\%, em 2009 e 25,3\%, em 2010. Esses dados apontam possivelmente para a efetividade das passagens de fauna, principalmente da PIF-118, na diminuição dos atropelamentos da espécie, automaticamente diminuindo o risco do usuário em se envolver em acidentes com essa espécie.

Outro dado relevante é que passagens de fauna com presença de água foram mais utilizadas do que passagens secas, sendo que 630 indivíduos de 15 espécies diferentes de mamíferos de médio e grande porte utilizaram as passagens com água, isso se deve ao fato da presença da água ser proveniente de córregos, rios e riachos que são cortados pela rodovia. Muitas espécies se deslocam por corredores vegetais que acompanham esses corpos d'água e as PIFs servem como uma continuação desses ambientes, possibilitando um maior número de travessias quando comparado às PIFs secas (Grillo et. al., 2008). Por exemplo, a passagem que registrou o segundo maior numero de travessias e também a maior riqueza de fauna foi a PIF-153, com 53 eventos e 11 espécies diferentes. Por ser uma passagem ampla, com água e antiga na paisagem, foi a primeira em número de riqueza de espécies (Figura 17), seguido da PIF 138 (que não apresenta água no interior da passagem mas apresenta uma distância mínima de 630 metros do Rio Jacaré Pepira) e PIF 107, com o registro de 8 espécies diferentes. 


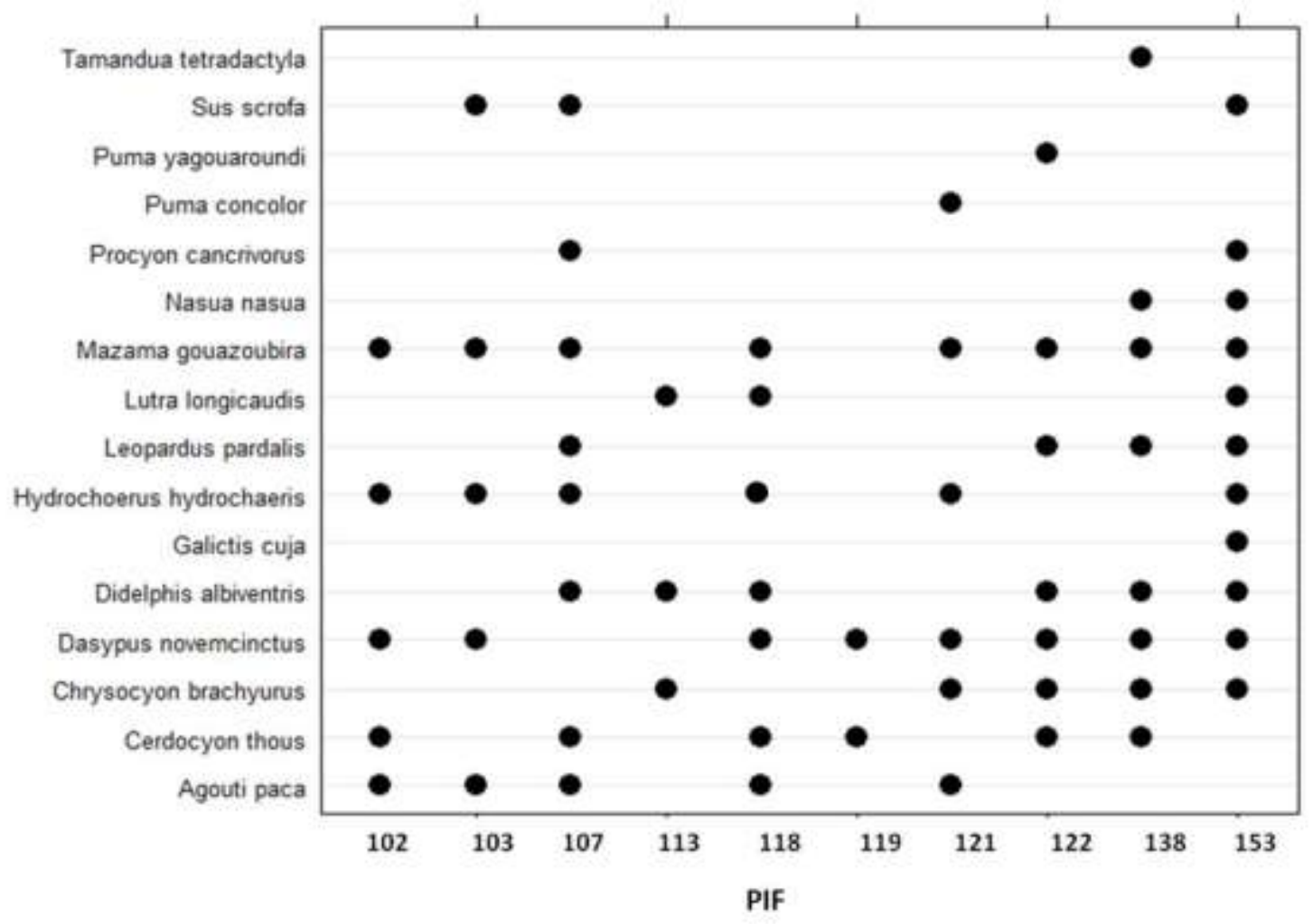

Figura 17 - Representação da riqueza de espécies em cada PIF estudada, com base na presença de cada espécie.

A importância da água no interior ou corpos d’água nas proximidades das PIFs para promover a travessia de espécies de mamíferos de médio e grande porte pode ser aplicada de forma prática durante o licenciamento de novas rodovias ou duplicações em que tubos de drenagem de água fluvial são possíveis de serem adaptados para a fauna. Nesse aspecto, os tubos ou galerias deveriam obedecer a tamanhos mínimos que contemplassem a travessia de mamíferos de médio e grande porte, e é possível que passagens celulares com dimensões de no mínimo $1,5 \mathrm{~m}$ x 1,5 m ou tubos circulares de no mínimo 1,5 m de diâmetro cumpram esse papel.

Da mesma forma, em áreas onde exista ocorrência de onça pintada (Panthera onca), anta (Tapirus terrestris) e alguns cervídeos de maior porte, os tamanhos mínimos sejam maiores que 2,5 m x 2,5 m para passagens celulares, é válido lembrar que não há implantação de tubos de drenagens circulares maiores que 2 metros de diâmetro, por 
questões de transporte e do solo exercer uma força que tubos circulares não são tão resistentes como as caixas de concreto para suportar.

Em vários países da América do Norte e Europa tubos de drenagem são adaptados para travessia da fauna, além de oferecerem tamanhos mínimos para os grupos faunísticos alvo. Também são implantadas plataformas secas nessas estruturas para que, em períodos de chuva, os animais possam ter uma via alternativa de deslocamento, já que o fluxo e o volume de água podem se tornar muito grandes, ou então, as passarelas contemplam também a travessia de espécies que não têm preferência por passagens úmidas (Figura 18).

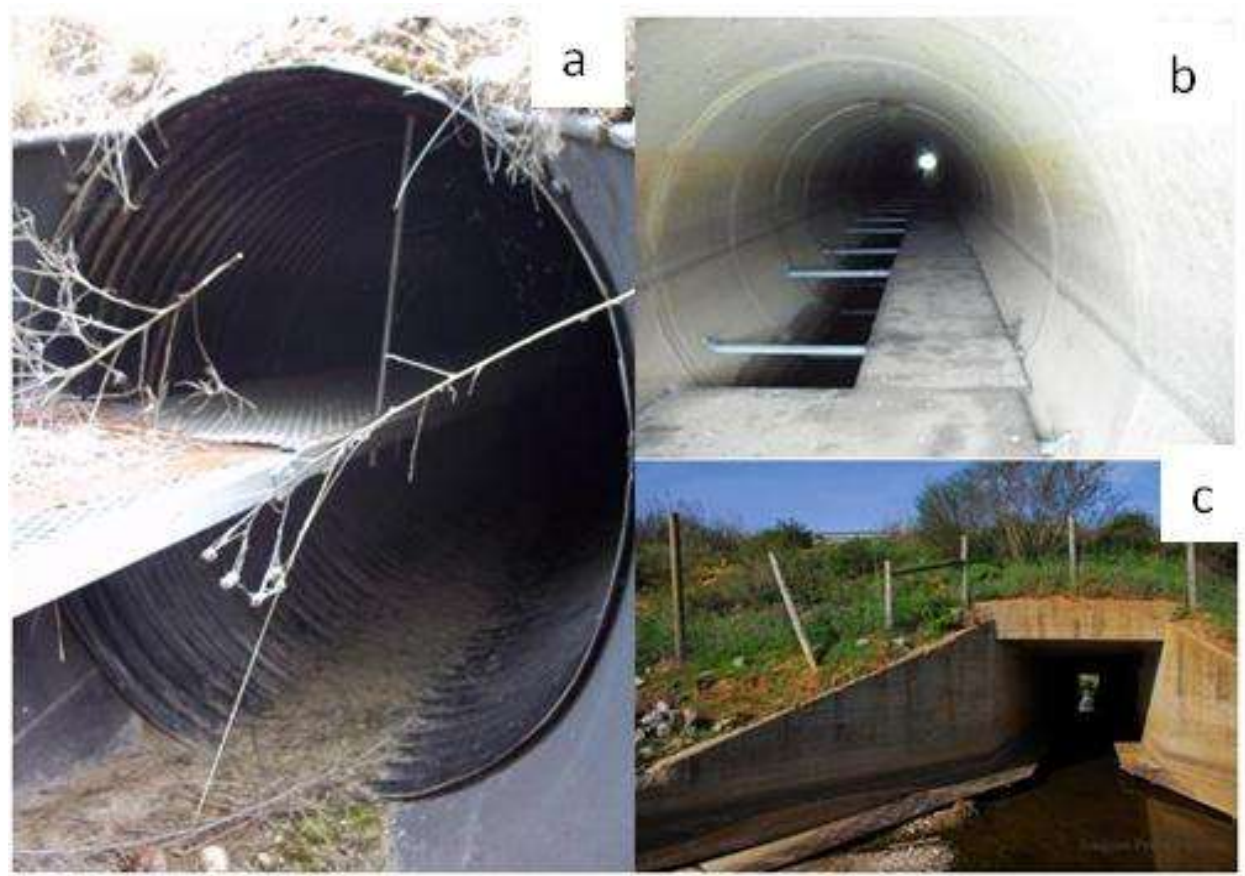

Figura 18: Exemplos de tubos e caixas de drenagens adaptados com passarelas: (a) passagem redonda de tubo Armco, Montana (EUA), (b) passagem redonda de concreto, Alentejo (Portugal), (c) Passagem quadrada de concreto, Vendas Novas (Portugal). (Foto: Fernanda Delborgo Abra.).

É válido lembrar que passagens fluviais com fluxo e volume de água naturalmente altos inviabilizaria o deslocamento desse grupo faunístico em especial, de forma que quanto mais larga as estruturas forem, menores serão o fluxo e volume de água dentro das passagens, aumentando as chances de mamíferos utilizarem essas 
estruturas, ou então, a construção de passagens anexas, ou seja, bem próximas às passagens com água, cumpririam o papel de encaminhar a fauna para as travessias.

Apesar de várias espécies apresentarem preferência por passagens úmidas, algumas espécies também sugeriram preferência total ou parcial pelas passagens secas, como o tamanduá mirim (Tamandua tetradactyla), o quati (Nasua nasua), a jaguatirica (Leopardus pardalis), o cachorro do mato (Cerdocyon thous) e o lobo guará (Chrysocyon brachyurus). Em passagens secas, foram registradas 22 travessias de lobo guará e 15 de cachorro do mato (Cerdocyon thous), enquanto que, em passagens com água, o lobo guará fez quatro travessias, seguido de três de cachorro do mato. Esse dado aponta uma possível predileção, principalmente, entre canídeos por passagens secas. A implicação prática desse dado é que embora passagens com água sugiram um maior número de travessias para espécies de mamíferos de médio e grande porte de modo geral, passagens secas permitem uma maior travessia entre carnívoros, em especial canídeos e, desta forma, a implantação de passagens secas não seja unicamente resguardar a segurança do usuário, mas sim, de promover a conservação da biodiversidade de grupos específicos. O lobo guará é espécie ameaçada de extinção no estado de São Paulo e no Brasil (Tabela 3) e o cachorro do mato, embora considerada uma espécie plástica e generalista foi considerada até o ano de 2004 como um dos canídeos menos estudados do mundo pela Canids Specialist Group/IUCN (IUCN, 2012).

De acordo com o Plano Nacional para a Conservação do Lobo Guará (PNC Lobo Guará) (ICMBio, 2012), para algumas populações, o atropelamento de lobos guarás em rodovias é responsável pela perda de aproximadamente um terço dos indivíduos adultos e também pela metade da produção anual de filhotes. Das 52 ações propostas para reduzir ou minimizar problemas e ameaças que comprometem a 
conservação da espécie, duas estão relacionadas à execução de projetos que quantifiquem e estimem o impacto dos atropelamentos nas populações de lobo guará.

Outro PNC foi realizado para onça parda (Puma concolor) (PNC - Onça Parda) (ICMBio, 2012) e, apesar de, no presente trabalho, a onça parda ter usado a PIF uma única vez durante todo o período de monitoramento, sabe-se que o atropelamento dessa espécie nas rodovias é comprometedor para sua permanência em vários biomas do país. No PNC da onça parda estão elencadas, dentre as 40 ações para conservação da espécie, cinco sobre Ecologia de Estradas, referentes às estimativas sobre perda de espécimes por atropelamento, efeito das estradas e rodovias sobre as populações, e ações para implantação de medidas de mitigação aos atropelamentos.

Comparação entre diferentes tipos de passagens

De acordo com a análise de variância efetuada, não houve diferença em preferência de uso entre tipos de passagens e isso se deve às passagens apresentarem, de modo geral, os mesmos tamanhos, em torno de $2 \mathrm{~m}$ x $2 \mathrm{~m}$ em passagens quadradas e 2 m de diâmetro para passagens redondas. É possível que, se fossem amostradas mais PIFs do tipo grande galeria, o sucesso de travessias seria maior. Com somente uma amostra desse tipo de passagem no presente trabalho, torna-se impossível mostrar se oferece maior sucesso em travessias em relação às outras PIFs analisadas.

A não diferença entre PIF novas e PIF antigas no sucesso de uso pela fauna provavelmente se deve ao fato das novas PIFs terem sido implantadas nos pontos estratégicos de atropelamentos, segundo banco de dados da Centrovias, indicados pelo Escritório Regional do IBAMA de Bauru durante a fase do licenciamento para duplicação da pista. Sendo assim, as novas passagens estariam suprindo a demanda de travessias dos animais que anteriormente se deslocariam pela rodovia, e quanto ao uso 
das PIFs antigas, as travessias se dão por essas passagens estarem a muito tempo na paisagem, as estruturas eram antigas passagens de gado que conectavam propriedades rurais separadas pela rodovia, as travessias de mamíferos de médio e grande porte nessas antigas passagens podem ser explicadas pela questão de aprendizado deste grupo em especial, uma vez que os mamíferos usam as estruturas e são bem sucedidos nas travessias, as PIFs passam a fazer parte das rotas diárias e áreas de vida de várias espécies (Ascensão \& Mira, 2006).

Passagens inferiores de fauna em rodovias sob concessão no estado de São Paulo

Ainda que passagens de fauna já venham sendo implantadas em algumas rodovias, o número atual dessas estruturas, na escala estadual, é irrisório. De acordo com a Artesp (2011), durante os anos de 2005 até julho de 2010, 12 concessionárias, cobrindo uma extensão de $3571,78 \mathrm{~km}$, sendo que $2609,52 \mathrm{~km}$ em pistas duplas e 962,26 em pistas simples contabilizaram 20.652 atropelamentos de animais silvestres.

Para que as passagens de fauna exerçam de fato um aumento da conectividade na escala estadual, seria necessário que todas as rodovias tivessem passagens de fauna numa frequência de espaçamento médio de implantação. Sabe-se que as passagens devem ser empregadas em lugares específicos e estratégicos da rodovia e a distância mínima entre passagens devem variar de acordo com o grupo taxonômico almejado para mitigação. No entanto, não se sabe qual a distância mínima que seria necessária entre as passagens de fauna na rodovia estudada. Mesmo em países em que os estudos de Ecologia de Estradas estão avançados, não existem números definidos para nenhum grupo taxonômico. No caso deste estudo, seria conveniente calcular a média de deslocamento diário das espécies do grupo faunístico a ser contemplado pelas PIFs e, a 
partir disso, calcular a distância mínima necessária entre PIFs para cada espécie de interesse, bem como uma distância média para a fauna de vertebrados da região, em geral. Assim, na área deste estudo, a distância mínima entre PIFs deveria ser tirada da média do deslocamento desde o gambá (Didelphis albiventris), que foi a menor espécie registrada dentro do grupo focal de mamíferos de médio e grande porte, até a onça parda (Puma concolor), a maior espécie de mamíferos de médio e grande porte com ocorrência na área. Como não foi possível obter, neste estudo ou na literatura, os valores de deslocamento das espécies de mamíferos de médio e grande porte da área de estudo, sugerimos que a distância mínima entre PIFs seja de 3 a $4 \mathrm{~km}$, variando de 0,33 até 0,25 $\mathrm{PIF} / \mathrm{km}$ para rodovias que não estejam situadas próximas ou dentro de Unidades de Conservação, bem como rodovias presentes nas Áreas prioritárias para Conservação (Figura 19), indicadas pelo programa Biota/FAPESP - Fundação de Apoio à Pesquisa do Estado de São Paulo (Metzger, 2008). Essa distância estaria baseada em alguns estudos na América do Norte que apontam uma variação entre 0.38 passagem de fauna/km e 0.56 passagem de fauna/km (Foster \& Humphrey 1995; Clevenger et al. 2002; Dodd et al. 2007). Essa distância entre PIF contemplaria em sua grande parte a travessia de mamíferos de médio e grande porte, deixando a desejar a mitigação de atropelamento para outros grupos como: répteis, aves, anfíbios e pequenos mamíferos. No caso de rodovias que cortem ou margeiem Unidades de conservação, bem como as áreas prioritárias para conservação, principalmente áreas que necessitam de ações prioritárias para conservação do tipo "incremento de conectividade", sugere-se que a distância entre PIF seja menor que em rodovias localizadas fora dessas áreas, portanto, inferiores a $3 \mathrm{~km}$ de distância. 


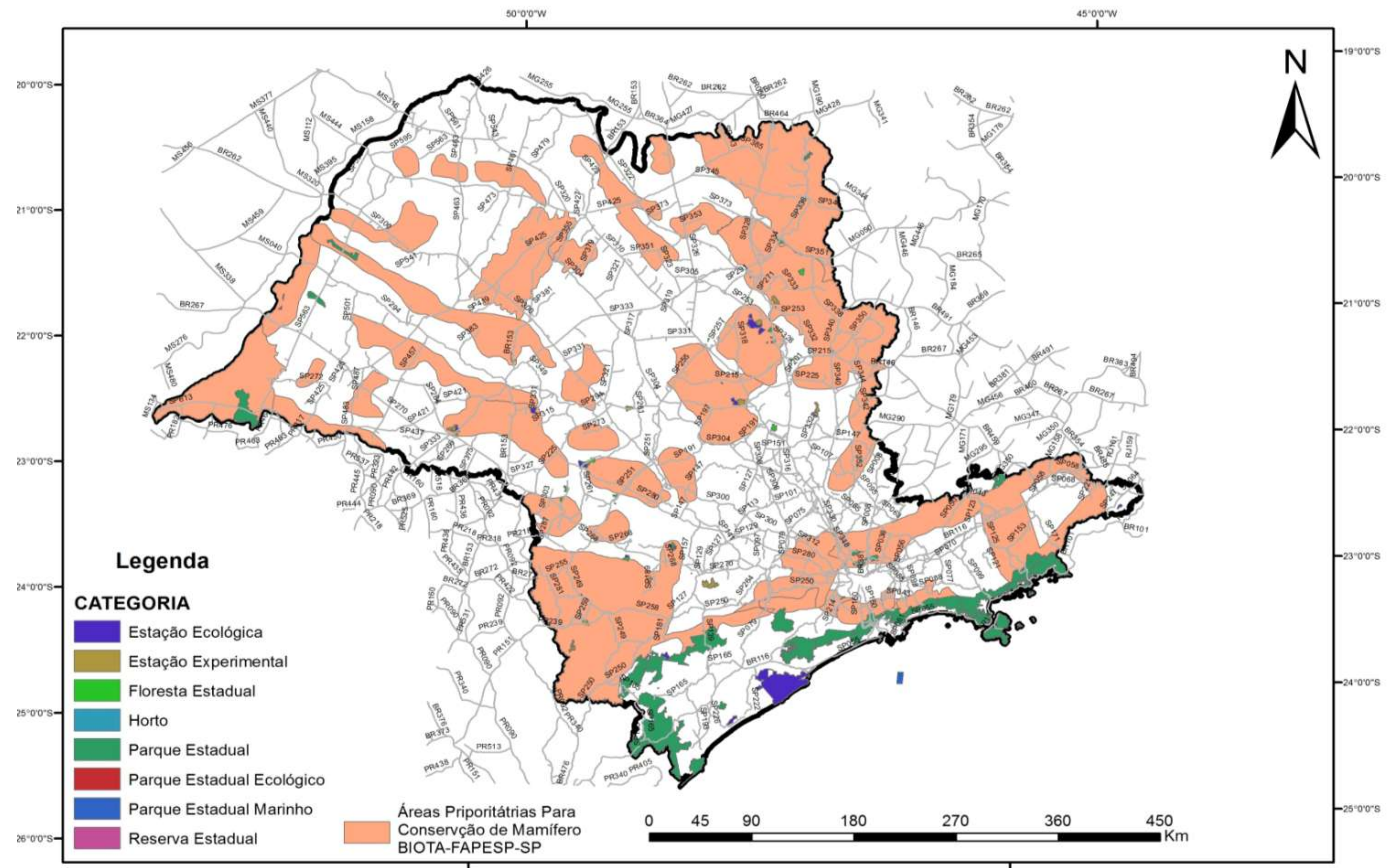

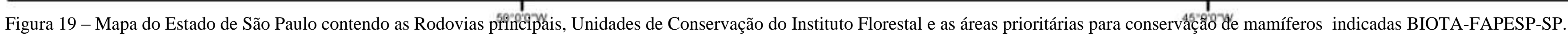




\section{Considerações Finais}

Este estudo mostrou existir preferência de algumas espécies de mamíferos de médio e grande porte por passagens inferiores de fauna com presença ou ausência de água. Embora os dados não tenham permitido verificar significância, é provável que também haja preferência da fauna quanto à forma e à estrutura da PIF, bem como o tipo de matriz, a quantidade de habitat circundante e outras estruturas da paisagem que influenciam no deslocamento de algumas espécies próximas às rodovias e que implicam na percepção e uso dessas estruturas numa escala local.

Apesar das limitações de baixo número amostral, os resultados desse trabalho representam uma primeira iniciativa no sentido de avaliar a efetividade de PIFs e já permitem subsidiar melhorias na implantação de passagens inferiores de fauna em licenciamentos de novas rodovias ou duplicações, em ecossistemas semelhantes aos que foram testados com os resultados apontados neste estudo.

É necessário que novos monitoramentos de PIFs sejam feitos e que o órgão licenciador de rodovias do estado de São Paulo, CETESB, possa criar resoluções ou qualquer outro tipo de instrumento legal para a padronização da implantação de medidas mitigatórias nas rodovias do Estado. Urge a necessidade de uma política preventiva, de um planejamento ambiental eficiente, da padronização de medidas de mitigação para fauna, em especial, e de diretrizes compensatórias em obras de infraestrutura rodoviária no Estado de São Paulo e no Brasil como um todo. No estado de São Paulo, detentor da maior malha rodoviária do país, o cenário ambiental é bastante preocupante, pois os níveis de fragmentação dos habitats naturais são os mais altos do Brasil (Metzger \& Rodrigues, 2008), fazendo com que várias espécies já se apresentam em pequenas populações isoladas, sendo, portanto, necessário que todo e qualquer esforço que 
previna, mitigue e compense esse impacto seja executado, visando tanto a segurança do usuário, quanto a conservação da biodiversidade. 


\section{Referências Bibliográficas}

ASCENSÃO, F.; MIRA, A., 2006. Factors Affecting Culvert Use by Vertebrates Along two Stretches of Road in Southern Portugal. Ecol Res, 22: 57 -66.

ARROYAVE, M. P; GÓMEZ, C., 2006. Impacto de las Carreteras sobre la Fauna Silvestre y sus Principales Medidas de Manejo. Revista EIA, 5: 45-57.

ARTESP - Agência Reguladora de Transportes do Estado de São Paulo, 2011. Disponível em: http://www.artesp.sp.gov.br/. Acessado em: 15 de junho de 2011.

BAKER, P.J.; HARRIS, S.; ROBERTSON, C.P.J.; SAUNDERS, G.; WHITE, P.C.L., 2004. It is possible to monitor mammal population changes from counts of Road traffic casualities? An analysis using Bristol's red foxes Vulpes vulpes as an example. Mammal Review, 34: 115-130.

BARRIENTOS, R.; BOLONIO, L., 2008. The presence of rabbits adjacent to roads increases polecat Road mortality. Biodiversity Conservation, 18:405-418.

BECKER, M.; DALPONTE, C. J. 1991. Rastros de mamíferos silvestres brasileiros: um guia de campo. Brasília: Universidade de Brasília, 181 p.

BECKMANN, J.P.; CLEVENGER, A.P.; HUIJSER, M.P.; HILTY, J.A., 2010. Safe Passages: highways, wildlife, and habitat connectivity. Island Press, Washington, USA.

BERGALlO, H. G.; VERA y CONDE, C. F., 2001. O Parque Nacional do Iguaçu e a Estrada do Colono. Ciência Hoje, 29: 37-39.

BERGER, J., 2007. Fear, human shields, and the re-distribution of prey and predators in protected areas. Biology letters 3: 620-623.

BISSONETTE, J.A.; ADAIR, W., 2008. Restoring habitat permeability to roaded landscapes with isometrically-scaled wildlife crossings. Biological Conservation, 141: 482-488.

BOARMAN, W.I.; SAZAKI, M.; JENNINGS, B., 1997. The effect of roads, barrier fences, and culverts on Desert Tortoise populations in California, USA. Proceedings: Conservation, Restoration and Management of tortoises and turtles - An International Conference, pp. 54-58.

BOND, A.R.; JONES, D.N., 2008. Temporal trends in use of fauna-friendly underpasses and overpasses. Wildlife Research, 35: 103-112.

BRITO, J.C.; ÁLVARES, F.J., 2004. Patterns of Road mortality in Vipera latastei and V. seoanei from northern Portugal. Amphibia Reptilia, 25: 459-465.

BRUINDERINK, G.W.T.A.G.; HAZEBROEK, E., 1996. Ungulate traffic collisions in Europe. Conservation Biology, 10: 1059-1067. 
CAIN, A.T.; TUOVILA, V.R.; HEWITT, D.G.; TEWES, M.E., 2003. Effects of a highway and mitigation projects on bobcats in Southern Texas. Biological Conservation, 114: 189-197.

CBT - Código Brasileiro de Trânsito, 2006. Anexo I e II. Curitiba, Brasil, 56p.

CENTROVIAS - Grupo OHL Brasil, 2012. Disponível em: http://www.centrovias.com.br/. Acessado em: 20 de janeiro de 2012.

CLARKE, G.P.; WHITE, P.C.L.; HARRIS, S., 1998. Effects of roads on badger Meles meles metapopulations in south-west England. Biological Conservation, 86: $117-124$.

CLEVENGER, A.P.; CHRUSZCZ, B.; GUNSON, K., 2001. Drainage culverts as habitat linkages and factors affecting passage by mammals. Journal of Applied Ecology, 38: 1340-1349.

CLEVENGER, A.P.; CHRUSZCZ, B.; GUNSON, K. \& WIERZCHOWSKI, J.. 2002. Roads and wildlife in the Canadian Rocky Mountain Parks: movements, mortality and mitigation. Final report to Parks Canada. Banff, Alberta, Canada.

CLEVENGER, A.P.; WALTHO, N., 2003. Long-term, year-round monitoring of wildlife crossing structures and the importance of temporal and spatial variability in performance studies. IN: Proceedings of the 2003 International Conference on Ecology and Transportation, Eds. Irwin, C.L; Garret, P.; McDermott, K.P. Center for Transportation and the Environment, North Carolina State University, Raleigh, NC:293-302.

CLEVENGER, A.P.; WALTHO, N., 2005. Performance indices to identify attributes of highway crossing structure facilitating movement of large mammals. Biological Conservation, 121: 453-464.

CORLATTI, L.; HACKLANDER, K.; FREY-ROOS, F., 2009. Ability of wildlife overpasses to provide connectivity and prevent genetic isolation. Conservation Biology, s/n: 1-9.

D’ANGELO, G.J.; D’ANGELO J.G.; GALLAGHER, G.R.; OSBORN, D.A.; MILLER, K.V.; WARREN, R.J., 2006. Evaluation of wildlife warning reflectors for altering White-tailed deer bahavior along roadways. Wildlife Society Bulletin 34: 1175-1183.

DELGADO, J. M. et al. 2004. Plano de Manejo Integrado das Unidades de Itirapina-SP. São Pulo: IF, 153 p. (Série Registros, n. 27).

DER - Departamento de Estradas e Rodagem, 2012. Disponível em: http://www.der.sp.gov.br/website/Home/. Acessado em: 20 de janeiro de 2012. 
DODD JR, C.K.; BARICHIVICH, W.J.; SMITH, L.L., 2004. Effectiveness of a barrier wall and culverts in reducing wildlife mortality on a heavily traveled highway in Florida. Biological Conservation, 118: 619-631.

DODD, N.L.; GAGNON, J.W.; BOE, S.; MANZO, A. \& SCHWEINSBURG, R.E.. 2007. Evaluation of measures to minimize wildlife-vehicle collisions and maintain permeability across highways: Arizona Route 260. Final Report 540. FHWA-AZ-07-540. Arizona Department of Transportation, Phoenix, Arizona, USA.

ECOVIAS, Grupo Ecovias, 2011. Disponível em: http://www.ecovias.com.br/. Acessado em: 20 de junho de 2011.

EVINK, G.L., 2002. Interections between roadways and wildlife ecology. National cooperative highway research program, Transportation Research Bord, National Research Council, Washington, DC.

FALCUCCI, A.; CIUCCI, P.; MAIORANO, L.; GENTILE, L.; BOITANI, L., 2009. Assessing habitat quality for conservation using an integrated ocurrencemoratlity model. Journal of Applied Ecology, 46:600-609.

FERREIRA, Z.F., 2010. Mapeamento do uso e cobertura das terras e análise da estrutura da paisagem do entorno das rodovias SP-225 e SP-310. Monografia de Iniciação Científica , 17 f. Instituto de Biociências, Universidade de São Paulo, SP.

FORMAN, R. T. T.; ALEXANDER, L. E., 1998. Roads and Their Major Ecological Effects. Annual Review in Ecology and Systemattics, 29: 207-231.

FORMAN, R.T.T.; SPERLING, D.; BISSONETTE, J.; CLEVENGER, A.; CUTSHALL, C.; DALE, V.; FAHRIG, L.; FRANCE, R.; GOLDMAN, C.; HEANUE, K.; JONES, J.; SWANSON, F.; TURRENTINE, T.; WINTER, T., 2003. Road ecology: science and solutions. Island Press, Washington.

FOSTER, M.L.; HUMPHREY, S.R., 1995. Use of highway underpasses by florida panthers and other wildlife. Wildlife Society Bulletin, 23:95-100.

FUNDAÇÃO FLORESTAL DO ESTADO DE SÃO PAULO. 2012. Disponível em: http://www.fflorestal.sp.gov.br/. Acessado em: 20 de julho de 2012.

GASCON, C.; LOVEJOY, T.E.; BIERREGAARD JUNIOR, R.O.; MALCOLM, J.R.; STOUFFER, P.C.; VASCONCELOS, H.L.; LAURANCE, W.F.; ZIMMERMAN, B.; TOCHER, M.; BORGES, S. 1999. Matrix habitat and species richness in tropical forest remnants. Biological Conservation, 91: 223229.

GILPIN, M.; HANSKI, I. 1991. Metapopulation dynamics: empirical and theoretical investigations. Academic Press, London, 313 p. 
GODWIN, B.J.; FAHRIG, L., 2002. How does landscape structure influence landscape connectivity? Oikos, 99: 552- 570.

GOMES, L.; GRILO, C.; SILVA, C.; MORA, A., 2008. Identification methods and determinist factors of owl roadkill hotspot locations in Mediterranean landscapes. Ecological Research, 24: 355-370.

GOOSEM, M., 2004. Linear infrastructure in the tropical rainforests of far North Queensland: Mitigating impactson fauna of roads and powerline clearings. Conservation of Australia's forest fauna, p. 418-434.

GOOSEM, M., 2007. Fragmentation impacts caused by roads trought rainforests. Current Science, 93: 1587-1593.

GRAVES, T.A.; FARLEY, S.; SERVHEEN, C., 2006. Frequency and Distribution of Highway Crossings by Kenai Peninsula Brown Bears. Wildlife Society Bulletin, 34: 800-808.

GRILO, C.; BISSONETTE, J.A.; SANTOS-REIS, M., 2008. Response of carnivores to existing highway culverts and underpasses: implications for roads planning and mitigation. Biodiversity Conservation, 17: 1685-1699.

GRILO, C,; BISSONETE, J.A.; SANTOS-REIS, M., 2009. Spatial-temporal patterns in Mediterranean carnivore road casualities: Consequences for mitigation. Biological Conservation, 142: 301-313.

GUTER, A.; DOLEV, A.; SALTZ, D.; KRONFELD-SCHOR, N., 2005. Temporal and spatial influences on road mortality in otters: conservation implications. Israel Journal of Zoology, 51: 199-207.

HAAS, C.D., 2000. Distribution, Relative Abundance and Roadway Underpass Responses of Carnivores Troughout the Puente-Chino Hills. A Thesis presented to the Faculty of California State Polytechnic University, Pomona.

HAUER, S.; ANSORGE, H.; ZINKE, O., 2002. Mortality patterns of otters (Lutra lutra) from eastern Germany. Journal of Zoology, 256: 361-368.

HESS, G. R.; FISCHER, R. A. 2001. Communicating clearly about conservation corridors. Landscape and Urban Planning. 55:195-208.

HUIJSER, M.P.; McGOWEN, P.T.;MFULLER, J.; HARDY, A.; KOCIOLEK, A.; CLEVENGER, A.P.; SMITH, D.; AMENT, R., 2007. Wildlife vehicle collision reduction study. Report to U.S Congress. U.S Department of Transportation, Federal Highway Administration, Washington DC.

IBAMA - Instituto Brasileiro de Meio Ambiente e dos Recursos Naturais Renováveis. Disponível em: http://www.ibama.gov.br/. Acessado em: 20 de junho de 2012. 
IBGE - Instituto Brasileirode Geografia e Estatística, 2012. Disponível em: http://www.ibge.gov.br/. Acessado em 20 de janeiro de 2012.

ICMBIO - Instituto Chico Mendes para a Conservação da Biodiversidade. Disponível em: http://www.icmbio.gov.br/. Acessado em 20 de janeiro de 2012.

IUCN - Red List of Threatened Species. 2012. Disponível em: http://www.iucnredlist.org/ . Acessado em: 20 de janeiro de 2012.

IUELL, B; BEKKER, G.J.; CUPERUS, R.; DUFEK, J.; FRY, G.; HICKS, C.; HLAVÁC, V.; KELLER, V.; ROSELL, B.; SANGWINE, T.; TØRSLØV, N.; WANDALL, B.I.M, 2003. Wildlife and Traffic: a European handbook for identifying conflicts and designing solutions. KNNV Publishers, Brussels, Belgium.

KACZENSKY, P.; KNAUER, F.; KRZE, B.; JONOZOVIC, M.; ADAMIC, M.; GOSSOW, H., 2003. The impact of high volume traffic axes on brown bears in Slovenia. Biological Conservation, 111: 191-204.

KRUUK, H.; CONROY, J.W.H., 1991. Mortality of otters (Lutra lutra) in Shetland. The Journal of Applied Ecology, 28: 83-94.

LITTLE, S.J.; HARCOURT, R.G.; CLEVENGER, A.P., 2002. Do wildlife passages act as prey traps? Biological Conservation, 107: 135-145.

LODÉ, T., 2000. Effect of a motorway on mortality and isolation of wildlife populations. Ambio, 29: 163-166.

LOKSCHIN, L.X; PRINTES, R.C.; CABRAL, J.N.H.; BUSS, G., 2007. Power Lines and Howler Monkey conservation in Porto Alegre, Rio Grande do Sul, Brasil.

Neotropical Primates 14: 76-80.

LOVARI, S.; SFORZI, A.; SCALAZ, C.; FICO, R., 2007. Mortality parameters of the Wolf in Italy: does the Wolf keep himself from the door? Journal of Zoology, 272: 117124.

MACARTHUR, R.H.; WILSON, E.O. 1967. The theory of island biogeography. Princeton Univ. Press. Ed., Princeton.

McDONALD, W.; CLAIR, C.C., 2004. Elements that promote highway crossing structure use by small mammls in Banf National Park. Journal of Applied Ecology, 41: 82-93.

MMA. Ministério do Meio Ambiente, 2005 - Secretaria de Biodiversidade e Florestas. Fragmentação de Ecossistemas: Causas, Efeitos sobre a Biodiversidade e Recomendações de Políticas Públicas. 2. ed. Brasília: MMA/SBF.

MATA, C.; HERVÁS, I.; HERRANZ, J.; SUARÉZ, F.; MALO, J.E., 2005. Complementary use by vertebrates of crossing structures along a fenced Spanish motorway. Biological Conservation, 124: 397-405. 
MATA, C.; HERVÁS, I.; HERRANZ, J.; SUARÉZ, F.; MALO, J.E., 2007. Are Motorway Wildlife Passages Worth Building? Vertebrate use of Road-Crossing Structures on a Spanish Motorway. Journal of Environmental Management, 88: 407-415.

MASS, V.; RATOKOMANGA, B.; RAKOTONDRATSIMBA, G.; RAZAFINDRAMISA, S.; ANDRIANAIVOMAHEFA, P., DICKINSON, S.; BERNER, P.O.; COOKE, A., 2011. Lemur bridges provide crossing structures over roads within a forested mining concession near Moramanga, Toamasina Province, Madagascar. Conservation Evidence, 8: 11-18.

METZGER, J.P.1999. Estrutura da paisagem e fragmentação: análise bibliográfica. In: Anais da Academia Brasileira de Ciências, Rio de Janeiro. Anais. Rio de Janiero: v.71, n.3-1, p. 445-463.

METZGER, J.P. 2001. O que é ecologia de paisagens? Biota Neotrop. 1(1/2): http://www.biotaneotropica.org.br/v1n12/pt/abstract?temathicreview+BN00701 122001 (Acessado em 20/01/2012).

METZGER, J. P. ; RODRIGUES, R. R. 2008. Mapas sínteses de diretrizes para a conservação e restauração da biodiversidade no Estado de São Paulo. In: Rodrigues, R.R.; Joly, C.A.; Brito, M.C.W.; Paese, A.; Metzger, J.P.; Casatti, L.; Nalon, M.A.; Menezes, N.; Ivanauskas, N.M.; Bolzani, V.; Bononi, V.L.R.. (Org.). Diretrizes para conservação e restauração da biodiversidade no Estado de São Paulo. 1 ed. São Paulo: Governo do Estado de São Paulo, v. 1, p. 130-136.

MYSTERUD, A., 2004. Temporal variation in the number of car-killed red deer Cervus elaphus in Norway. Wildlife Biology, 10: 203-211.

Ng, S.J.; DOLE, J.W.; SAUVAJOT, R.M.; RILEY, S.P.D.; VALONE, T.J., 2004. Use of highway undercrossings by wildlife in southern California. Biological Conservation, 115: 499-507.

NIMER, E., 1989: Climatologia do Brasil. Instituto Brasileiro de Geografia e Estatística, Rio de Janeiro, RJ; 421 p.

OLSSON, M.P.O.; WIDÉN, P.; LARKIN, J.L., 2008. Effectiveness of a Highway Overpass to Promote Landscape Connectivity and Movement of Moose and Roe Deer in Sweden. Landscape Urban Plann.

PAC - PROGRAMA DE ACELERAÇÃO AO CRESCIMNETO.2011. Disponível em: http://www.brasil.gov.br/pac/. Acessado em: 20 de junho de 2011.

PERIS, S.; MORALES, J., 2004. Use of passages across a canal by wild mammals and related mortality. European Journal of Wildlife Research, 50: 6772.

PMI - Prefeitura Municipal de Itirapina, 2012. Disponível em: http://www.itirapina.sp.gov.br/portal/. Acessado em: 20 de julho de 2012. 
PONÇANO, W.L.; CARNEIRO, C.D.R.; BISTRICHI, C.A.; ALMEIDA, F.F.M. de; PRANDINI, F.L. 1981. Mapa Geomorfológico do Estado de São Paulo. São Paulo: Instituto de Pesquisas Tecnológicas, 94 p.

PRADA, C. S., 2004. Atropelamento de vertebrados silvestres em uma região fragmentada do Nordeste do estado de São Paulo: quantificação do impacto e análise de fatores envolvidos. 130f. Dissertação (Mestrado em Ecologia e Recursos Naturais) - Centro de Ciências Biológicas e da Saúde da Universidade de São Carlos - UFSCar.

RODRÍGUEZ, A.; CREMA, G.; DELIBES, M., 1997. Factors affecting crossing of red foxes and wildcats through non-wildlife passages across a high-speed railway. Ecography 20: 287-294.

SEILER, A. 2003. The toll of the automobile: Wildlife and roads in Sweden. Thesis, Swedish University of Agricultural Sciences, Uppsala, Sweden.

SEILER, A., 2005. Predicting locations of moose-vehicle collisions in Sweden. Journal od Applied Ecology, 42: 371-382.

SIELECKI, L.E, 2001. Evaluating the effectiveness of wildlife accident mitigation installations with the wildlife accident reporting system (WARS) in British Columbia. IN: Proceedings of the 2001 International Conference on Ecology and Transportation, Eds. Irwin CL, Garrett P, McDermott KP. Center for Transportation and the Environment, North Carolina State University, Raleigh, NC: 473-489.

SETZER, J., 1966. Atlas Climático e Ecológico do Estado de São Paulo. Comissão Interestadual da Bacia Paraná-Uruguai, 61p.

TAYLOR, B.D.; GOLDINGAY, R.L., 2004. Wildlife Road-Kills on Three Major Roads in North-Eastern New South Wales. Wildlife Research, 31: 83-91.

TROCMÉ, M., 2006. Habitat Fragmentation Due to Linear Transportation Infraestructure: An Overview of Mitigation Measures in Switzerland. Swiss Transport Research Conference. March 15 - 17.

TROMBULAK, S.C.; FRISSELL, C.A., 2000. Review of ecological effects of Roads on Terrestrial and Aquatic Communities. Conservation Biology, 14: 1830 .

VAN VUURDE, M.R., VAN DER GRIFT, E.A., 2005. The effects of landscape attributes on the use of small wildlife underpasses by weasel (Mustela nivalis) and stoat (Mustela ermine).Lutra $48: 91-108$.

YANES, M.; VELASCO, J.M.; SUÁREZ, F., 1995. Permeability of roads and railways to vertebrates: The importance of culverts. Biological Conservation, 71: 217-222. 
ZAR, J. H. 1999. Biostatistical Analysis. Prentice-Hall International Editions, New Jersey. 
8. Anexos

Anexo 1 - Mídia digital contendo os vídeos das travessias das PIFs estudadas. 